Atmos. Chem. Phys., 21, 10727-10743, 2021

https://doi.org/10.5194/acp-21-10727-2021

(c) Author(s) 2021. This work is distributed under

the Creative Commons Attribution 4.0 License.

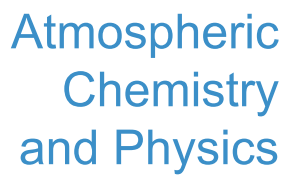

(c) (P)

\title{
Spectrometric measurements of atmospheric propane $\left(\mathrm{C}_{3} \mathrm{H}_{8}\right)$
}

\author{
Geoffrey C. Toon ${ }^{1}$, Jean-Francois L. Blavier ${ }^{1}$, Keeyoon Sung ${ }^{1}$, and Katelyn Yu ${ }^{1,2}$ \\ ${ }^{1}$ Jet Propulsion Laboratory, California Institute of Technology, Pasadena, CA 91109, USA \\ ${ }^{2}$ Civil and Environmental Engineering, University of California, Berkeley, CA 94720, USA
}

Correspondence: Geoffrey C. Toon (geoffrey.c.toon@jpl.nasa.gov)

Received: 29 October 2020 - Discussion started: 2 December 2020

Revised: 12 April 2021 - Accepted: 4 May 2021 - Published: 14 July 2021

\begin{abstract}
We report measurements of atmospheric $\mathrm{C}_{3} \mathrm{H}_{8}$ from analysis of ground-based solar absorption spectra from the Jet Propulsion Laboratory (JPL) MkIV interferometer. Using the strong $Q$-branch absorption feature at $2967 \mathrm{~cm}^{-1}$, we can measure $\mathrm{C}_{3} \mathrm{H}_{8}$ in locations where its abundance is enhanced by proximity to sources (e.g., large natural gas fields, megacities). A case study of MkIV $\mathrm{C}_{3} \mathrm{H}_{8}$ measurements from Fort Sumner, New Mexico, shows that amounts are strongly correlated with ethane $\left(\mathrm{C}_{2} \mathrm{H}_{6}\right)$ and with backtrajectories from SE New Mexico and western Texas, where the Permian Basin oil and natural gas field is located. Measurements from JPL, California, also show large $\mathrm{C}_{3} \mathrm{H}_{8}$ enhancements on certain days but more correlated with $\mathrm{CO}$ than $\mathrm{C}_{2} \mathrm{H}_{6}$. From high-altitude balloon-borne MkIV solar occultation measurements, $\mathrm{C}_{3} \mathrm{H}_{8}$ was not detected at any altitude $(5-40 \mathrm{~km})$ in any of the 25 flights.
\end{abstract}

\section{Introduction}

Non-methane hydrocarbons such as $\mathrm{C}_{3} \mathrm{H}_{8}$ and $\mathrm{C}_{2} \mathrm{H}_{6}$ affect air quality, because their oxidation enhances tropospheric $\mathrm{O}_{3}$ and aerosol pollution. They are also sensitive indicators of fugitive losses by the oil and natural gas industry and an important source of co-emitted methane $\left(\mathrm{CH}_{4}\right)$, which is a greenhouse gas. These fugitive losses appear to be underestimated in global inventories (Dalsøren et al., 2018).

Atmospheric $\mathrm{C}_{3} \mathrm{H}_{8}$ and $\mathrm{C}_{2} \mathrm{H}_{6}$ are entirely the result of emissions at the surface. In preindustrial times these came from geological seeps and wild fires, but in recent times these natural sources have been surpassed by emissions from fossil fuel production. The latter peaked in about 1970 and then declined due to stricter regulation of emissions from the oil and natural gas industry and automobiles. But in the past decade, this decreasing trend has reversed due to accelerated natural gas (NG) exploitation (Helmig et al., 2016).

$\mathrm{C}_{3} \mathrm{H}_{8}$ has a lifetime of about 2 weeks in summer and 8 weeks in winter (Rosado-Reyes and Francisco, 2007). This is mostly dictated by how fast it is being oxidized by reactions with hydroxyl radicals and chlorine atoms. Given this 2-8-week lifetime, a single strong source of propane has the potential to degrade air quality over most of the hemisphere.

Unprocessed in-the-ground "wet" natural gas is usually between $70 \%-95 \% \mathrm{CH}_{4}, 1 \%-15 \% \mathrm{C}_{2} \mathrm{H}_{6}, 1 \%-10 \% \mathrm{C}_{3} \mathrm{H}_{8}$, and $0 \%-3 \% \mathrm{C}_{4} \mathrm{H}_{10}$. The last two gases are typically extracted to form liquified petroleum gas (LPG). In the Northern Hemisphere (NH) winter, LPG contains more $\mathrm{C}_{3} \mathrm{H}_{8}$, while in summer it contains more butane $\left(\mathrm{C}_{4} \mathrm{H}_{10}\right)$, reducing variations in its vapor pressure.

LPG burns much more cleanly than fuel oil and is therefore increasingly used for heating and cooking, especially in rural areas that are not served by piped NG. LPG is also used to fuel commercial vehicles, and it is increasingly replacing CFCs as a refrigerant and as an aerosol propellant. As a result of extracting LPG from natural gas, the NG that is piped to our homes in urban areas is highly depleted in $\mathrm{C}_{3} \mathrm{H}_{8}$ and $\mathrm{C}_{4} \mathrm{H}_{10}$, as compared with wet NG.

To the best of our knowledge, there are no previous remote sensing measurements of $\mathrm{C}_{3} \mathrm{H}_{8}$, although in situ measurements exist. Dalsøren et al. (2018, Fig. 3b) show surface in situ $\mathrm{C}_{3} \mathrm{H}_{8}$ amounts below $50 \mathrm{ppt}$ at Zeppelin station in Svalbard in summer 2011 but with values of $1 \mathrm{ppb}$ in the winter and with peaks of up to $2.4 \mathrm{ppb}$. These $\mathrm{C}_{3} \mathrm{H}_{8}$ peaks are strongly correlated with $\mathrm{C}_{2} \mathrm{H}_{6}$ which reaches $3.4 \mathrm{ppb}$. Using in situ $\mathrm{C}_{3} \mathrm{H}_{8}$ data from multiple sites Helmig et al. (2016) show a large seasonal cycle in surface in situ $\mathrm{C}_{3} \mathrm{H}_{8}$ at high $\mathrm{NH}$ latitudes, reaching $1 \mathrm{ppb}$ in winter with little in the Southern Hemisphere (SH). They also show increasing $\mathrm{C}_{3} \mathrm{H}_{8}$ 
over central and eastern US over the period mid-2009 to mid2014 but no increase on the west coast.

Since $\mathrm{C}_{3} \mathrm{H}_{8}$ correlates with $\mathrm{C}_{2} \mathrm{H}_{6}$, both having $\mathrm{NG}$ as their main source, we also consider the previous measurements of $\mathrm{C}_{2} \mathrm{H}_{6}$, which has a lifetime of 2-8 months (4 times longer than propane). Angelbratt et al. (2011) reported a $0 \%-2 \% \mathrm{yr}^{-1}$ decline over the period 1996 to 2006 based on data from six NH FTIR sites. Franco et al (2015) reported a shallow minimum in $\mathrm{C}_{2} \mathrm{H}_{6}$ in the 2005-2010 period based on ground-based FTIR solar spectra above the Jungfraujoch scientific station. Helmig et al. (2016) report a minimum in atmospheric $\mathrm{C}_{2} \mathrm{H}_{6}$ in 2005-2010 based on in situ and remote measurements.

Franco et al. (2016) estimate a $75 \%$ increase in North American $\mathrm{C}_{2} \mathrm{H}_{6}$ emissions between 2008 and 2014, and as a result they report a $3 \%-5 \%$ annual increase in column $\mathrm{C}_{2} \mathrm{H}_{6}$ at northern mid latitudes. They hypothesize that this increase is the result of the recent massive growth in the exploitation of shale gas and tight oil reservoirs in North America, where the drilling productivity began to grow rapidly after 2009 .

\section{Methods}

\subsection{MkIV instrument}

The Jet Propulsion Laboratory (JPL) MkIV interferometer (Toon, 1991) is a high-resolution FTIR spectrometer built at JPL in 1984. It covers the entire $650-5650 \mathrm{~cm}^{-1}$ range simultaneously in every spectrum with two detectors: a $\mathrm{HgCdTe}$ photoconductor covering $650-1800 \mathrm{~cm}^{-1}$ and an InSb photodiode covering $1800-5650 \mathrm{~cm}^{-1}$. For ground-based observations, a maximum optical path difference (OPD) of $117 \mathrm{~cm}$ is employed, providing a spectral resolution of $0.005 \mathrm{~cm}^{-1}$. The MkIV is primarily a balloon instrument and has performed 25 flights since 1989, with the latest in 2019. Between balloon flights it makes ground-based observations. Since 1985 it has taken 5000 ground-based observations on 1200 different days from 12 different sites. For more detail, see tables in the following URL: https://mark4sun.jpl.nasa. gov/ground.html, last access: 20 June 2021.

\subsection{Retrieval}

The analysis of the MkIV spectra was performed with the GFIT (gas fitting) tool, which is a nonlinear least-squares spectral-fitting algorithm developed at JPL. GFIT has been previously used for the version 3 analysis (Irion et al., 2002) of spectra measured by the Atmospheric Trace Molecule Occultation Spectrometer, and it is currently used for analysis of Total Carbon Column Observing Network (TCCON) spectra (Wunch et al., 2011) as well as for MkIV spectra (Toon et al., 2016, 2018a, b). The entire package, including spectral fitting software, spectroscopic line lists, and software to generate a priori VMR / $T$ / $P$ profiles, is termed GGG.
GFIT scales the atmospheric gas volume mixing ratio (VMR) profiles to fit calculated spectra to those measured. For $\mathrm{C}_{3} \mathrm{H}_{8}$, a $5.4 \mathrm{~cm}^{-1}$ wide fitting window centered on the $Q$-branch at $2967 \mathrm{~cm}^{-1}$ was used. The atmosphere was discretized into 70 layers of $1 \mathrm{~km}$ thickness. $\mathrm{C}_{3} \mathrm{H}_{8}$ and four interfering gases $\left(\mathrm{H}_{2} \mathrm{O}, \mathrm{CH}_{4}, \mathrm{C}_{2} \mathrm{H}_{6}, \mathrm{HDO}\right)$ were adjusted. Two frequency stretches were retrieved (telluric and solar). The spectral continuum was fitted as a straight line, and a zerolevel offset was fitted. So that is a total of 10 simultaneously fitted scalars. In addition, the solar pseudo-transmittance was computed (but not adjusted).

The assumed temperature, pressure, and $\mathrm{H}_{2} \mathrm{O}$ profiles were based on the National Centers for Environmental Prediction (NCEP) 6-hourly analyses for solar noon of each day. The a priori VMR profiles were based on NH mid-latitude profiles. This is the same scheme as used by the GGG TCCON analysis (Wunch et al., 2015), but here we apply it to the mid-IR MkIV spectra rather than the shortwave IR TCCON spectra.

To estimate the sensitivity of the retrieved $\mathrm{C}_{3} \mathrm{H}_{8}$ to uncertainties in the assumed a priori profiles of $T / P$ and interfering gases (especially $\mathrm{H}_{2} \mathrm{O}, \mathrm{CH}_{4}$ ), we retrieve the post-2000 $\mathrm{C}_{3} \mathrm{H}_{8}$ a second time: using GGG2020, an updated version of the GGG code with improved a priori VMR / $T$ / $P$ profiles based on the GEOS-FP-IT analysis. The results, shown in Fig. B2, illustrate that this changes the retrieved $\mathrm{C}_{3} \mathrm{H}_{8}$ by less than $10 \%$ with a bias of only $1.1 \%$.

\subsection{Spectroscopy}

It is clear from the infrared lab spectrum of $\mathrm{C}_{3} \mathrm{H}_{8}$ (Fig. 1), measured at Pacific Northwest National Laboratory (PNNL; Sharpe et al., 2004), that the feature at $2967 \mathrm{~cm}^{-1}$, caused by various $\mathrm{CH}_{2}$ and $\mathrm{CH}_{3}$ stretching vibrational modes, is by far the strongest in the entire infrared. So for solar occultation spectrometry, this is by far the best choice. For thermal emission spectrometry from cold astronomical bodies such as Titan, however, these bands are not covered by Cassini/CIRS since the thermal Plank function of such bodies weakens rapidly above $2000 \mathrm{~cm}^{-1}$. Thus, the much weaker bands below $1400 \mathrm{~cm}^{-1}$ must be used (Sung et al., 2013).

An empirical pseudo-line-list (EPLL) of $\mathrm{C}_{3} \mathrm{H}_{8}$ covering $2560-3280 \mathrm{~cm}^{-1}$ was derived from the laboratory cross sections of Harrison and Bernath (2010). This is described in the following unpublished report: https://mark4sun.jpl.nasa. gov/data/spec/Pseudo/c3h8_pll_2560_3280.pdf, last access: 20 June 2021.

The use of an EPLL facilitates interpolation and extrapolation of the lab cross sections to $T / P$ conditions that were not measured in the lab. The fitting of the EPLL also checks the self-consistency of the lab cross-section spectra and provides an opportunity for us to correct for artifacts in the lab spectra (e.g., channeling, zero-level offsets, contamination, instrument line shape (ILS), although it must be stated that in this particular case the $\mathrm{C}_{3} \mathrm{H}_{8}$ lab spectra 


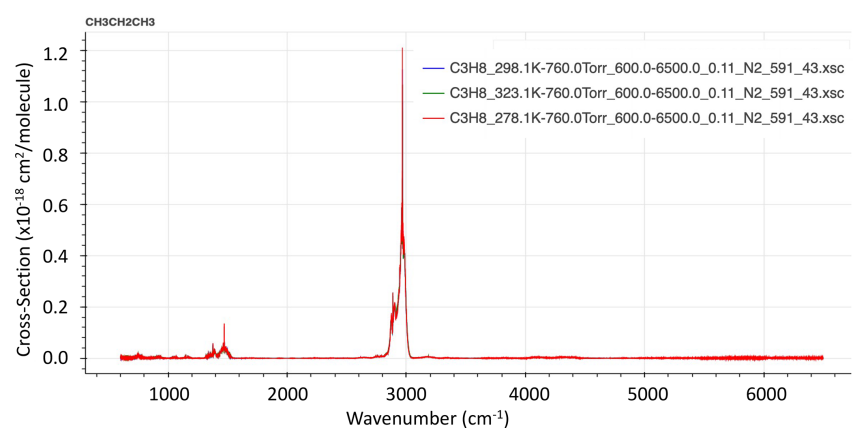

Figure 1. Infrared spectra of $\mathrm{PNNL} \mathrm{C}_{3} \mathrm{H}_{8}$ absorption cross section at 323,298 , and $278 \mathrm{~K}$ (from hitran.org).

were of very high quality and comprehensive in terms of their coverage. For the interfering $\mathrm{C}_{2} \mathrm{H}_{6}$, an EPLL developed 8 years ago was used, based on lab measurements of Harrison et al. (2010), as described in the following report: https://mark4sun.jpl.nasa.gov/report/C2H6_spectroscopy_ evaluation_2850-3050_cm-1.compressed.pdf, last access: 20 June 2021.

For other gases, the atm.161 line list was used, which is based on HITRAN 2016, with some empirical adjustments based on fits to lab spectra, especially for $\mathrm{H}_{2} \mathrm{O}$ and $\mathrm{CH}_{4}$. This is basically the same line lists (atm.161, pll.101) that are used by TCCON, but here we use them in the mid-infrared (MIR) rather than the shortwave infrared (SWIR).

Figure 2 shows an average spectral fit to the $\mathrm{C}_{3} \mathrm{H}_{8}$ window in ground-based MkIV spectra, obtained by fitting individual spectra and then averaging the results. The lower panel provides the full transmittance $y$ range from 0 to 1 . It can be seen that the main absorbers are $\mathrm{CH}_{4}$ (orange) and $\mathrm{H}_{2} \mathrm{O}$ (green). The $\mathrm{C}_{3} \mathrm{H}_{8}$ absorption (red) is difficult to discern, because it is so shallow. The lower-middle panel shows the same spectral fit but with the $y$ scale zoomed into $0.95-1.00$ transmittance, allowing the weak absorbers like $\mathrm{C}_{3} \mathrm{H}_{8}$ and $\mathrm{C}_{2} \mathrm{H}_{6}$ to be more easily seen. The "other" contributions (e.g., $\mathrm{O}_{3}$ ) were included in the calculation but not adjusted. The $\mathrm{C}_{3} \mathrm{H}_{8}$ absorption is fairly flat at about $1 \%$ depth, except for the $Q$-branch where it deepens to $2.5 \%$. Although the strongest $\mathrm{C}_{2} \mathrm{H}_{6}$ feature coincides with the $\mathrm{C}_{3} \mathrm{H}_{8} Q$-branch, the former is much narrower and there are several additional $\mathrm{C}_{2} \mathrm{H}_{6}$ features in this window, so the spectrometric "cross-talk" between these two gases should be modest; we compute a Pearson correlation coefficient of -0.7 between the $\mathrm{C}_{3} \mathrm{H}_{8}$ and $\mathrm{C}_{2} \mathrm{H}_{6}$. Further discussion on this topic can be found in Appendix A. The upper-middle panel shows that the residuals (measured minus calculated transmittance) have some systematic features of $\sim 0.5 \%$ in magnitude, especially in the vicinity of the $\mathrm{H}_{2} \mathrm{O}$ line at $2966.0 \mathrm{~cm}^{-1}$. The topmost panel shows the residuals to a fit performed without any $\mathrm{C}_{3} \mathrm{H}_{8}$ absorption lines. It looks surprisingly similar to the fit performed with $\mathrm{C}_{3} \mathrm{H}_{8}$ lines, such is the ingenuity of the spectral fitting algorithm in adjusting the $\mathrm{H}_{2} \mathrm{O}, \mathrm{CH}_{4}$, and $\mathrm{C}_{2} \mathrm{H}_{6}$ to compensate for the missing $\mathrm{C}_{3} \mathrm{H}_{8}$. The overall $\mathrm{rms}$ residual in the no$\mathrm{C}_{3} \mathrm{H}_{8}$ case is $0.3934 \%$, as compared with $0.3658 \%$ when $\mathrm{C}_{3} \mathrm{H}_{8}$ is included. This is quite significant considering that residuals are dominated by the $\mathrm{H}_{2} \mathrm{O}$ line at $2966.0 \mathrm{~cm}^{-1}$ and are unaffected by whether $\mathrm{C}_{3} \mathrm{H}_{8}$ is included or not. The residuals in the topmost panel (d) are larger in the vicinity of the $\mathrm{C}_{3} \mathrm{H}_{8} Q$-branch, 2967-2968 $\mathrm{cm}^{-1}$, than those in panel (c).

Considering the weakness (and smoothness) of the $\mathrm{C}_{3} \mathrm{H}_{8}$ $Q$-branch in comparison with the residuals and the contributions of the other gases, we were at first skeptical that a useful $\mathrm{C}_{3} \mathrm{H}_{8}$ column measurement could be extracted from such spectral fits. But since the analysis of the MkIV spectra is highly automated, it took only a few hours to run the $\mathrm{C}_{3} \mathrm{H}_{8}$ window over all $5000 \mathrm{MkIV}$ ground-based spectra.

\section{Results}

Table 1 lists the observation sites from where MkIV has made ground-based observations up to the end of 2019. The vast majority are from three sites: JPL, Mount Barcroft, and Fort Sumner.

Figure 3 shows MkIV ground-based $\mathrm{C}_{3} \mathrm{H}_{8}$ columns, colorcoded by site altitude. The data were filtered: only points with uncertainties $<1.5 \times 10^{16}$ molecules $\mathrm{cm}^{-2}$ were plotted, reducing the number of plotted points from 5000 to 4700 . The top panel (a) shows that at the high-altitude sites (Mt. Barcroft at $3.8 \mathrm{~km}$ is red; Table Mountain Facility at $2.26 \mathrm{~km}$ is orange) the retrieved $\mathrm{C}_{3} \mathrm{H}_{8}$ columns are centered around zero. Also, the data acquired in September 1986 from $0.1 \mathrm{~km}$ in Antarctica (dark blue) are centered around zero. Data acquired from Ft. Sumner, New Mexico, at $1.2 \mathrm{~km}$ (lime green) have large variations, from zero to nearly $8 \times$ $10^{16}$ molecules $\mathrm{cm}^{-2}$, as do the data from JPL at $0.35 \mathrm{~km}$ (cyan). Other sites with detectable $\mathrm{C}_{3} \mathrm{H}_{8}$ include Daggett, California $(0.6 \mathrm{~km})$; Esrange, Sweden $(0.26 \mathrm{~km})$ in the winter; Fairbanks, Alaska (0.2 km); and Mountain View, California, in late 1991 . So $\mathrm{C}_{3} \mathrm{H}_{8}$ has only been measured by MkIV from Northern Hemisphere sites within the planetary boundary layer (PBL). Panels (b) and (c) show the same $\mathrm{C}_{3} \mathrm{H}_{8}$ columns but plotted versus year and day.

High $\mathrm{C}_{3} \mathrm{H}_{8}$ values $\left(>4 \times 10^{16}\right.$ molecules $\left.\mathrm{cm}^{-2}\right)$ can occur at any time of year at JPL (cyan) but most commonly in late summer, as is the case for other pollutants, e.g., CO. This reflects the meteorology (stagnant conditions in the LA basin in summer with little replacement of polluted air with clean air from outside). Averaging kernels for these $\mathrm{C}_{3} \mathrm{H}_{8}$ measurements are discussed and illustrated in Appendix B. Suffice it to say here that they range from 0.9 to 1.4 and increase with altitude.

The reported uncertainties in our $\mathrm{C}_{3} \mathrm{H}_{8}$ column measurements are based on the rms fitting residuals compared with the sensitivity of the spectrum to $\mathrm{C}_{3} \mathrm{H}_{8}$ (Jacobians). At the highest site, Mt. Barcroft at $3.8 \mathrm{~km}(P=0.65 \mathrm{~atm})$, where the interfering $\mathrm{H}_{2} \mathrm{O}$ and $\mathrm{CH}_{4}$ absorptions are relatively weak 
Table 1. The 12 sites from where MkIV has made ground-based observations, along with the number of observations and observation days from each site, years of operations, their location, and terrain type. The unbold sites have the fewest observations (only $1 \%$ of total) and are not included in Figs. 5-7 and A1 to reduced color ambiguity.

\begin{tabular}{|c|c|c|c|c|c|c|c|c|}
\hline Town & State & $N_{\text {obs }}$ & $N_{\text {day }}$ & Latitude $\left(^{\circ}\right)$ & Longitude $\left({ }^{\circ}\right)$ & Altitude $(\mathrm{km})$ & Terrain & Years operated \\
\hline Esrange & Sweden & 160 & 32 & 67.889 & +21.085 & 0.271 & Boreal & 1999-2007 \\
\hline Fairbanks & Alaska & 124 & 46 & 64.830 & -147.614 & 0.182 & Boreal & 1997 \\
\hline Lynn Lake & Manitoba & 20 & 11 & 56.858 & -101.066 & 0.354 & Boreal & 1996 \\
\hline Mt. Barcroft & California & 1369 & 258 & 37.584 & -118.235 & 3.801 & Alpine & 1994-2002 \\
\hline Mountain View & California & 7 & 4 & 37.430 & -122.080 & 0.010 & Urban & 1987,2001 \\
\hline Daggett & California & 33 & 21 & 34.856 & -116.790 & 0.626 & Desert & 1993 \\
\hline JPL (B183) & California & 2273 & 690 & 34.199 & -118.174 & 0.345 & Urban & 1985-2020 \\
\hline JPL (mesa) & California & 20 & 5 & 34.205 & -118.171 & 0.460 & Urban & $1988-1989$ \\
\hline Palestine & Texas & 4 & 3 & 31.780 & -95.700 & 0.100 & Rural & 1989 \\
\hline McMurdo & Antarctica & 37 & 20 & -77.847 & +166.728 & 0.100 & Polar & 1986 \\
\hline
\end{tabular}

and narrow, the $\mathrm{C}_{3} \mathrm{H}_{8}$ column uncertainties are generally smaller than $10^{15}$ molecules $\mathrm{cm}^{-2}$. But since the columns themselves are even smaller, no $\mathrm{C}_{3} \mathrm{H}_{8}$ is detected at Mt. Barcroft. At the lower-altitude sites such as JPL and Ft. Sumner, the increased interference from $\mathrm{H}_{2} \mathrm{O}$ and $\mathrm{CH}_{4}$ cause the $\mathrm{C}_{3} \mathrm{H}_{8}$ column uncertainties to be much larger, generally around $5 \times 10^{15}$ molecules $\mathrm{cm}^{-2}$ at low air mass and worsening rapidly toward higher air masses. But the $\mathrm{C}_{3} \mathrm{H}_{8}$ increases far more, allowing $\mathrm{C}_{3} \mathrm{H}_{8}$ to be detected at these low-altitude sites under polluted conditions, despite the poorer absolute uncertainties.

High $\mathrm{C}_{3} \mathrm{H}_{8}$ values are also seen at Ft. Sumner, New Mexico (lime green), especially in recent years. This was initially a surprise to us as this area has a very low population density, so we naively assumed that we would be measuring background levels of atmospheric pollutants here.

We know that the apparent variations in $\mathrm{C}_{3} \mathrm{H}_{8}$ are real, rather than artifacts, from their strong correlation with $\mathrm{C}_{2} \mathrm{H}_{6}$. Figure 4 compares column-averaged $\mathrm{C}_{3} \mathrm{H}_{8}$ mole fractions (top panels) with those of $\mathrm{C}_{2} \mathrm{H}_{6}$ (bottom panels), with the latter retrieved using different spectral lines than those shown in Fig. 2. These are the same total $\mathrm{C}_{3} \mathrm{H}_{8}$ columns shown in Fig. 3 but divided by the total column of all gases, which is inferred from the surface pressure. The resulting columnaverage mole fractions, denoted Xgas, are less sensitive to the site altitudes being different and more easily compared with in situ measurements being in units of mole fraction.

The upper and lower rows of Fig. 4 show the $\mathrm{XC}_{3} \mathrm{H}_{8}$ and $\mathrm{XC}_{2} \mathrm{H}_{6}$ time series, respectively, plotted versus year (left) and versus day of the year (right). The data were filtered such that only points with $\mathrm{XC}_{3} \mathrm{H}_{8}$ uncertainties $<0.74 \mathrm{ppb}$ and $\mathrm{C}_{2} \mathrm{H}_{6}$ uncertainties $<0.10 \mathrm{ppb}$ were plotted. This reduced the total number of points from 5000 to 4700 , so only the best $94 \%$ of the data are plotted. It is clear that at JPL (cyan) $\mathrm{C}_{3} \mathrm{H}_{8}$ has decreased since the 1990s, but at Ft. Sumner (lime green) it has increased over the past decade. The data from these two sites will be explored later.

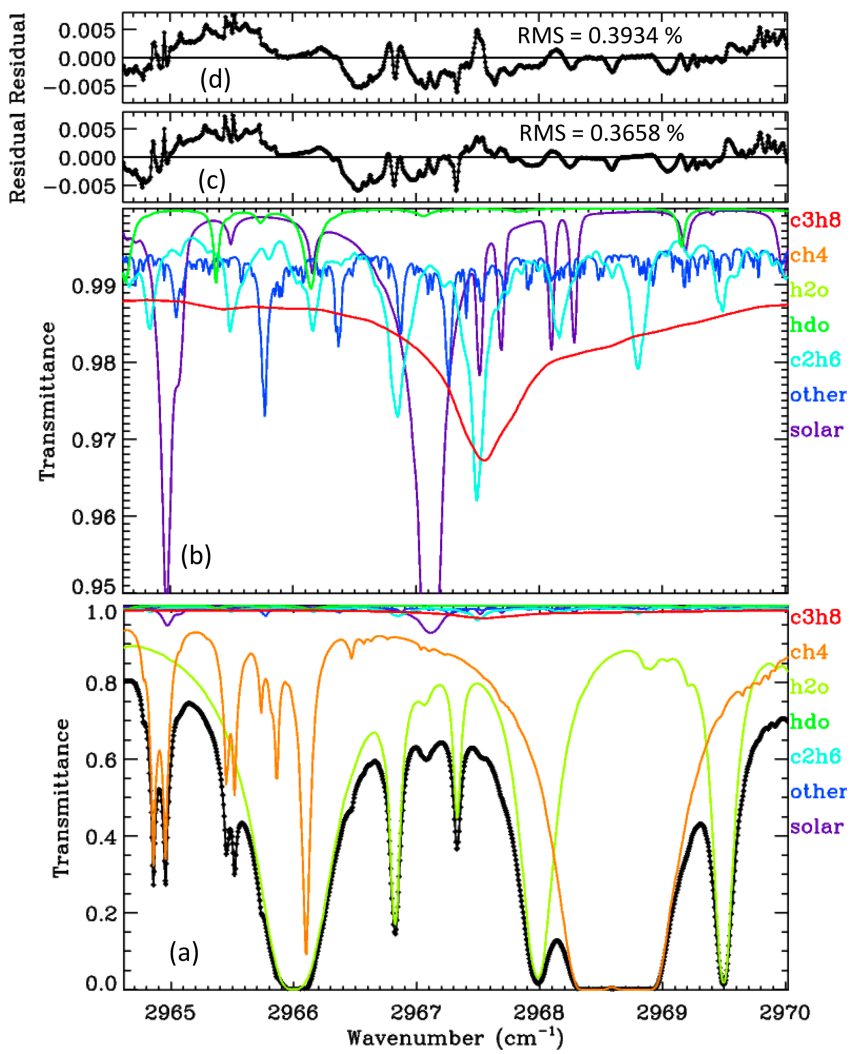

Figure 2. The average of 5000 ground-based MkIV spectral fits. Black diamonds represent the measured spectrum. Black line represents the fitted calculation. Colored lines represent the contributions of different gases. Panel (a) shows the full transmittance range. Panel (b) shows a zoomed-in view of the $0.95-1.00$ range to clearly show the weak absorbers $\left(\mathrm{C}_{2} \mathrm{H}_{6}, \mathrm{HDO}\right.$, and the solar lines). Panel (c) shows residuals (measured minus calculated); these are generally below $0.5 \%$. Panel (d) shows the residuals when $\mathrm{C}_{3} \mathrm{H}_{8}$ is excluded from the calculation. 

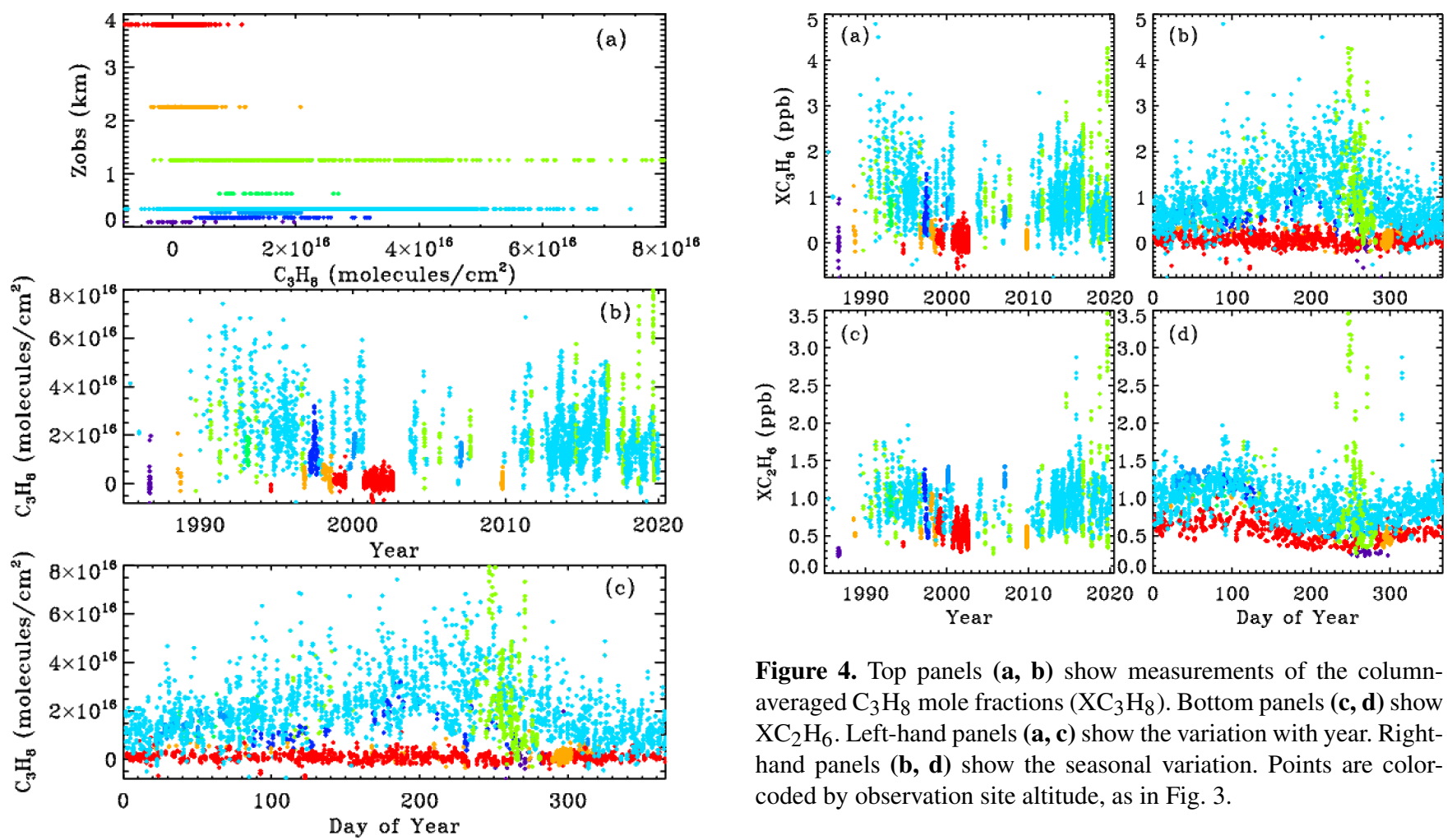

Figure 4. Top panels (a, b) show measurements of the columnaveraged $\mathrm{C}_{3} \mathrm{H}_{8}$ mole fractions $\left(\mathrm{XC}_{3} \mathrm{H}_{8}\right)$. Bottom panels $(\mathbf{c}, \mathbf{d})$ show $\mathrm{XC}_{2} \mathrm{H}_{6}$. Left-hand panels $(\mathbf{a}, \mathbf{c})$ show the variation with year. Righthand panels $(\mathbf{b}, \mathbf{d})$ show the seasonal variation. Points are colorcoded by observation site altitude, as in Fig. 3.

Figure 3. MkIV $\mathrm{C}_{3} \mathrm{H}_{8}$ column abundances from 8 out of 12 sites, color-coded by site altitude, as illustrated in panel (a): violet $=0.1 \mathrm{~km}$ (McMurdo); dark blue $=0.18 \mathrm{~km}$ (Fairbanks); light blue $=0.27 \mathrm{~km}$ (Esrange); cyan $=0.35 \mathrm{~km}(\mathrm{JPL}) ;$ green $=0.63 \mathrm{~km}$ (Daggett); lime green $=1.2 \mathrm{~km}$ (Ft. Sumner); orange $=2.26 \mathrm{~km}$ (TMF); red $=3.8 \mathrm{~km}$ (Mt. Barcroft).

$\mathrm{C}_{2} \mathrm{H}_{6}$ is 4 times longer-lived than $\mathrm{C}_{3} \mathrm{H}_{8}$ and never goes to zero, because there is always a substantial free tropospheric $\mathrm{C}_{2} \mathrm{H}_{6}$ component, even in the $\mathrm{SH}$, which varies seasonally: high in spring and low in fall. The Antarctic measurements (blue) are very low (0.2-0.3 ppb) and most probably even lower during the rest of the year, because days 250 to 300 represent the springtime peak not the fall. The highest $\mathrm{C}_{2} \mathrm{H}_{6}$ ever measured from JPL (cyan) was in late 2015 (day 314) as a result of the Aliso Canyon natural gas leak (Conley et al., 2016). This event is further discussed later and also in Appendix C.

Figure 5 shows the $\mathrm{XC}_{2} \mathrm{H}_{6} / \mathrm{XC}_{3} \mathrm{H}_{8}$ correlation plot for all sites. This uses the exact same data, filtering, and colorscheme as for Fig. 4. At JPL (cyan) the correlation is positive but weak. At Ft. Sumner, there are episodes of both gases being enhanced with a strong correlation. In fact, the highest VMRs of $\mathrm{C}_{2} \mathrm{H}_{6}$ were seen from Ft. Sumner, even more than from JPL during the Aliso Canyon gas leak in late 2015. 

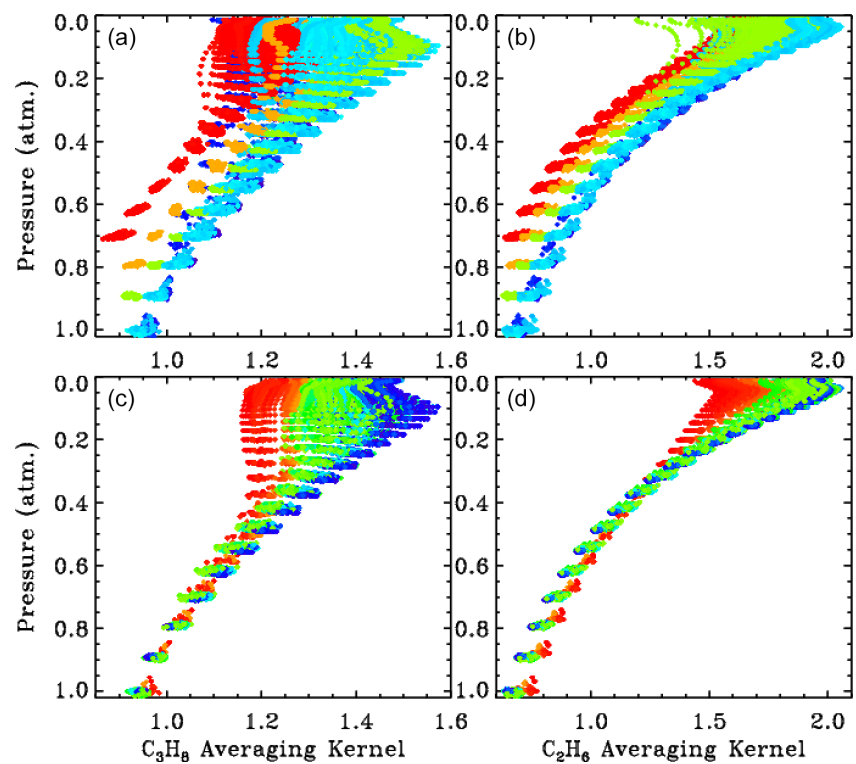

Figure 6. The 5000 averaging kernels for $\mathrm{C}_{3} \mathrm{H}_{8}$ are shown in the left-hand panels $((\mathbf{a}),(\mathbf{c}))$ and those for $\mathrm{C}_{2} \mathrm{H}_{6}$ are shown in the right-hand panels ((b), (d)). Upper panels ((a), (b)) show all kernels color-coded by site altitude, as in Fig. 3. Lower panels ((c), (d)) show kernels for the low-altitude sites $(0.25$ to $0.50 \mathrm{~km})$, which were all colored blue in the upper panels ((a) (b)) but are now colorcoded by solar zenith angle (blue $=15^{\circ}$; green $=60^{\circ}$; red $=80^{\circ}$ ).

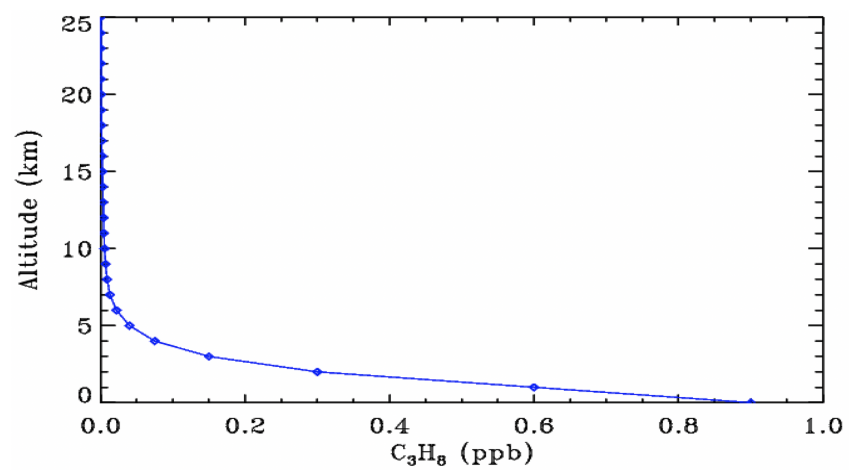

Figure 7. A priori $\mathrm{C}_{3} \mathrm{H}_{8}$ profile used in these retrievals.

panel, but in the lower panel they are color-coded by solar zenith angle (SZA). It is evident that the higher the SZA, the more uniform the kernels with altitude. The banding of the points in pressure space reflects the $1 \mathrm{~km}$ vertical grid on which the kernels were computed. The $\mathrm{C}_{3} \mathrm{H}_{8}$ kernels are also influenced by the $\mathrm{H}_{2} \mathrm{O}$ column and temperature, but these are smaller effects than those of site altitude or SZA.

Figure 7 show the assumed a priori VMR profile used in the retrievals and in the computation of the kernels. Since GFIT performs profile scaling retrievals, with a very weak a priori constraint, the absolute values of the VMRs play no role; only the profile shape matters.

\subsection{Case study: ground-based measurements from Ft. Sumner, New Mexico}

Ft. Sumner $\left(34.48^{\circ} \mathrm{N}, 104.22^{\circ} \mathrm{W} ; 1.2 \mathrm{~km}\right.$ a.s.l.) is the location of the main NASA facility for the launch of stratospheric research balloons. It is located there due to the low population density and hence low risk of mishap. The MkIV instrument has performed balloon campaigns in Ft. Sumner 18 times in the past 30 years. Not all of these campaigns have resulted in a flight, but we have always taken ground-based observations to check that the MkIV instrument is correctly aligned and functional and to check that telemetry, commanding tasks, and the operation of other experiments do not degrade the MkIV performance.

We have taken 520 observations on 106 different days from Ft. Sumner (out of a total of 5000 observations and 1200 different days). We examine these observations to try to understand whether the large day-to-day $\mathrm{C}_{3} \mathrm{H}_{8}$ variations are real and, if so, what is causing them. We have already seen a correlation between $\mathrm{XC}_{3} \mathrm{H}_{8}$ and $\mathrm{XC}_{2} \mathrm{H}_{6}$ at all sites in Fig. 5, but many points are buried under others, especially at the low values of $\mathrm{XC}_{3} \mathrm{H}_{8}$ and $\mathrm{XC}_{2} \mathrm{H}_{6}$.

Figure 8 shows that between 1990 and 2005 there was a decrease in $\mathrm{C}_{2} \mathrm{H}_{6}$ and $\mathrm{C}_{3} \mathrm{H}_{8}$ measured in Ft. Sumner, by about a factor of 2 over 15 years. In recent years (since 2014), however, there has been a large increase in $\mathrm{C}_{2} \mathrm{H}_{6}$ and $\mathrm{C}_{3} \mathrm{H}_{8}$ measured at Ft. Sumner but only when the wind direction is from the SE quadrant (green-cyan colors). We see no increase associated with other wind directions (red, blue, orange, yellow, lime green).

At Ft. Sumner, $\mathrm{CO}$ has no correlation with wind direction nor with $\mathrm{C}_{2} \mathrm{H}_{6}$ or $\mathrm{C}_{3} \mathrm{H}_{8}$. The majority of days have a column-average $\mathrm{CO}$ of $75 \pm 10 \mathrm{ppb}$. But there are occasional enhancements up to $120 \mathrm{ppb}$, likely due to large but distant fires. We do not pursue the Ft. Sumner CO data any further beyond proving that the $\mathrm{C}_{3} \mathrm{H}_{8}$ sources are different from those of $\mathrm{CO}$.

$\mathrm{CH}_{4}$ is also measured by MkIV. Over the 30-year measurement period, $\mathrm{XCH}_{4}$ has grown from 1650 to $1850 \mathrm{ppb}$. This secular increase is much larger than any variation due to wind direction. So to be useful, the $\mathrm{CH}_{4}$ data would have to be detrended, which is not simple given its nonlinear growth. Even within the past 4 years, the correlation of $\mathrm{XCH}_{4}$ with $\mathrm{XC}_{3} \mathrm{H}_{8}$ was very weak. This is to be expected since the background abundance of $\mathrm{CH}_{4}$ is more than 1000 times larger than $\mathrm{C}_{3} \mathrm{H}_{8}$, whereas wet NG is only 6 times richer in $\mathrm{CH}_{4}$ than $\mathrm{C}_{3} \mathrm{H}_{8}$ (in the Permian Basin). So the NG-induced enhancement of $\mathrm{CH}_{4}$, as a fraction of its atmospheric background level, will be much smaller than that of $\mathrm{C}_{3} \mathrm{H}_{8}$.

Figure 9 shows a $\mathrm{XC}_{3} \mathrm{H}_{8}-\mathrm{XC}_{2} \mathrm{H}_{6}$ scatter plot using just the Ft. Sumner data. Error bars are much larger for $\mathrm{XC}_{3} \mathrm{H}_{8}$ than for $\mathrm{XC}_{2} \mathrm{H}_{6}$. This is because the $\mathrm{C}_{2} \mathrm{H}_{6}$ transitions are stronger and form narrower features, both of which make the retrievals more precise and definitive, whereas most of the $\mathrm{C}_{3} \mathrm{H}_{8}$ absorption is smeared into a broad continuum which 

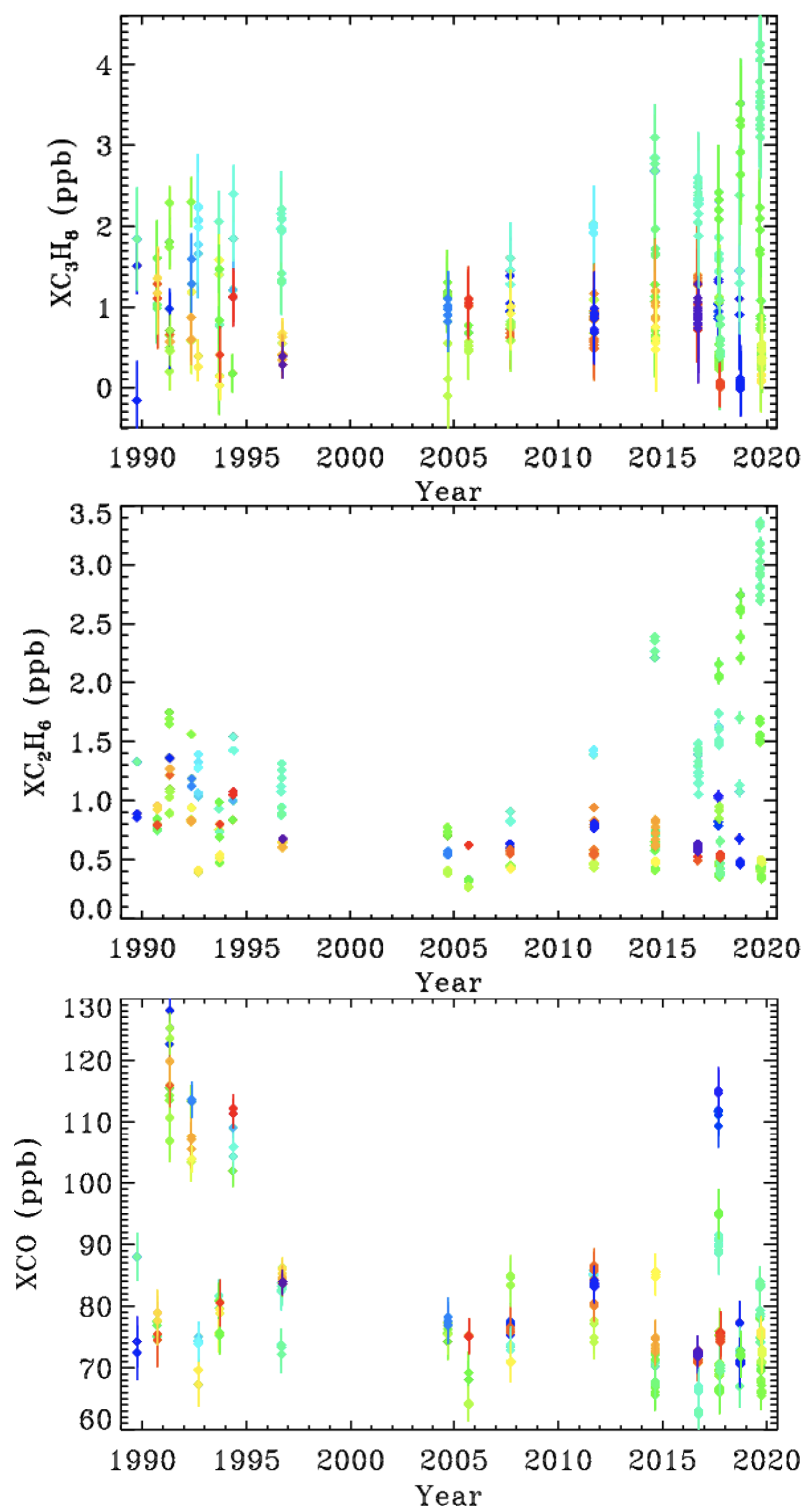

Figure 8. $X_{3} \mathrm{H}_{8}, X_{2} \mathrm{H}_{6}$, and $\mathrm{XCO}$ at Ft. Sumner. Since all the observations are made from the same altitude, it no longer makes sense to color-code by site altitude. So instead we colorcode by mean bearing of the back-trajectory over the previous $36 \mathrm{~h}$. Dark blue $=30^{\circ}$; light blue $=90^{\circ}$, cyan $=120^{\circ}$; green $=180^{\circ}$; lime green $=220^{\circ}$; orange $=300^{\circ}$; red $=350^{\circ}$. MkIV did not visit Ft. Sumner from 1997 to 2004, because it was performing highlatitude balloon flights from Alaska and Sweden.

provides little information for a retrieval in which the continuum level is fitted. The $\mathrm{C}_{2} \mathrm{H}_{6}$ features used in the actual $\mathrm{C}_{2} \mathrm{H}_{6}$ retrieval are at 2976.6 and $2986.6 \mathrm{~cm}^{-1}$ (not shown) and are 3-4 times stronger than those seen in Fig. 2.

The gradient of the fitted line is $0.78 \pm 0.10$, implying more $\mathrm{C}_{3} \mathrm{H}_{8}$ than $\mathrm{C}_{2} \mathrm{H}_{6}$. The Pearson correlation coefficient is 0.85 , which is high considering the large error bars on the $\mathrm{XC}_{3} \mathrm{H}_{8}$, and the fact that the similarity of their Jacobians

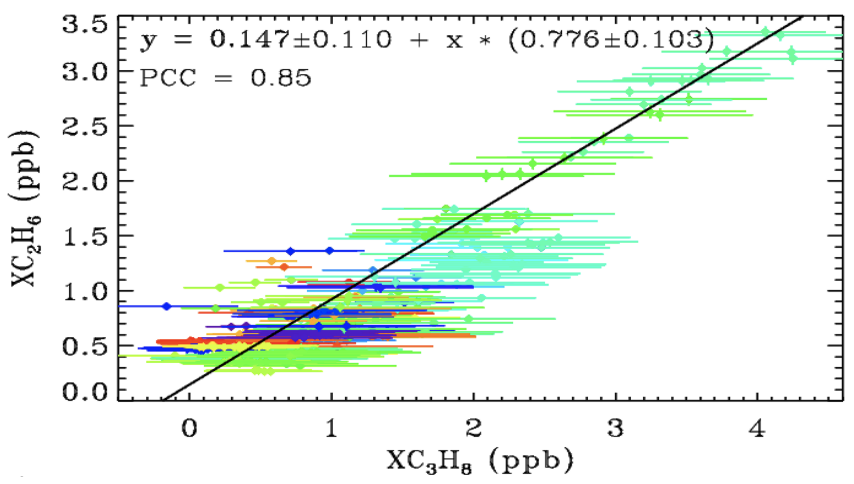

Figure 9. The relationship between $\mathrm{XC}_{3} \mathrm{H}_{8}$ and $\mathrm{XC}_{2} \mathrm{H}_{6}$ at Ft. Sumner, color coded for wind direction as for Fig. 8.

would imply an anticorrelation in their retrieved amounts (Appendix A). This tight relationship at Ft. Sumner suggests that the large variations in the $\mathrm{C}_{3} \mathrm{H}_{8}$ measurements are not an artifact. Since $\mathrm{C}_{2} \mathrm{H}_{6}$ can be easily and precisely measured by this technique, it is hard to imagine it being changed by a factor of 5 from day-to-day by an artifact. Much more likely the common variations in both $\mathrm{C}_{3} \mathrm{H}_{8}$ and $\mathrm{C}_{2} \mathrm{H}_{6}$ are real.

As already hinted, for each of the 106 observation days from Ft. Sumner, we ran hourly HYSPLIT back-trajectories (Stein et al., 2015; Rolph et al., 2017) that bracket the MkIV observation times and then interpolated linearly in time between the two bracketing trajectories. This provided a unique trajectory for each of the 520 observations from Ft. Sumner. The North American Regional Reanalysis (NARR) meteorology was selected, which covers North America at $32 \mathrm{~km}$ resolution. This is the highest-resolution meteorology that covers the entire 1989-2019 observation period. A trajectory altitude of $0.4 \mathrm{~km}$ over Ft. Sumner was selected, and these trajectories were extended to $36 \mathrm{~h}$ before the observations in $1 \mathrm{~h}$ steps. Figure 10 shows that the large variations of $\mathrm{C}_{3} \mathrm{H}_{8}$ are strongly correlated with wind direction. It is very clear that trajectories originating from the SE of Ft. Sumner carry more $\mathrm{C}_{3} \mathrm{H}_{8}$ than those from any other direction. A plot was made also for $\mathrm{C}_{2} \mathrm{H}_{6}$ but not shown due to its strong similarity to Fig. 10.

We also made a scatter plot for CO (not shown) but there was no correlation between $\mathrm{CO}$ and wind direction or between $\mathrm{CO}$ and $\mathrm{C}_{3} \mathrm{H}_{8}$. This rules out the possibility that the enhanced $\mathrm{C}_{3} \mathrm{H}_{8}$ and $\mathrm{C}_{2} \mathrm{H}_{6}$ were somehow associated with distant urban pollution or wild fires.

This result leads to speculation on what might be enhancing $\mathrm{C}_{2} \mathrm{H}_{6}$ and $\mathrm{C}_{3} \mathrm{H}_{8}$ when the winds come from the $\mathrm{SE}$ sector. One of the biggest natural gas production fields in the US lies in the Permian Basin, which underlies the southeast corner of New Mexico and western Texas, as illustrated in Fig. 10. This region also includes processing plants where the heavier gases are stripped out of the wet NG, storage facilities for the resulting natural gas liquids (LPG + ethane + pentane), and pipelines. The Permian Basin is by far the largest 


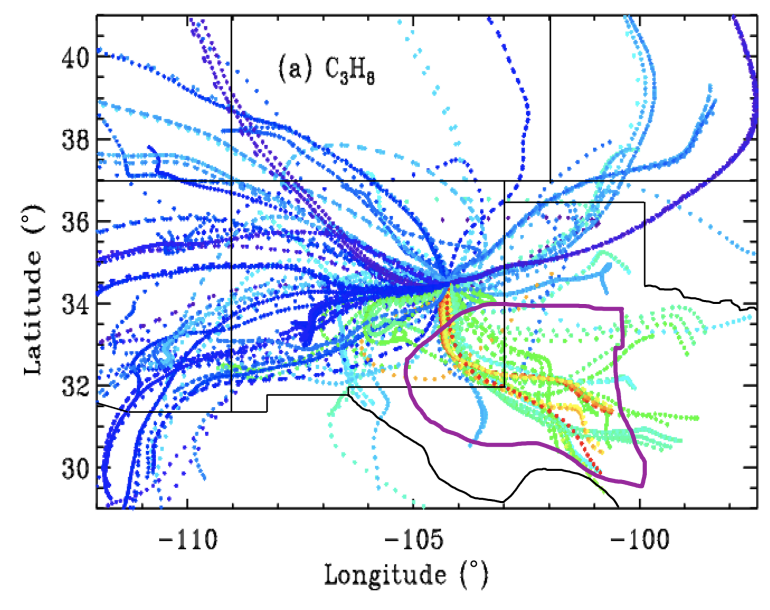

Figure 10. Hourly locations for the back-trajectories, color-coded by retrieved $\mathrm{XC}_{3} \mathrm{H}_{8}$. Blue $=0$, green $=2$, red $=4 \mathrm{ppb}$. Trajectories for which the $\mathrm{XC}_{3} \mathrm{H}_{8}$ uncertainty exceeded $0.74 \mathrm{ppb}$ are excluded, resulting in only 373 out of 520 trajectories being shown. Ft. Sumner lies at $34.2^{\circ} \mathrm{N}, 104.2^{\circ} \mathrm{W}$, which is close to the center of the figure at the confluence of all the back-trajectories. Each point represents a $1 \mathrm{~h}$ time step, so the wind speed is apparent from the separation of points. Winds from the west are typically stronger than those from the SE quadrant. Trajectories are underlaid by a map of New Mexico and neighboring states. The Permian Basin, encircled by the thick purple line, underlies SE New Mexico and much of western Texas. Many of the trajectories from the SE have spent more than $30 \mathrm{~h}$ over the Permian Basin.

"liquids-rich" (rich in heavy hydrocarbons) gas field in the USA (https://www.spglobal.com/platts/plattscontent/ _assets/_images/latest-news/20191219-rig-count.jpg, last access: 20 June 2021). This would suggest that the enhanced $\mathrm{C}_{2} \mathrm{H}_{6}$ and $\mathrm{C}_{3} \mathrm{H}_{8}$ are the result of losses from NG production, although this cannot be proven with just one instrument at one site. We would need instruments upwind and downwind to make an accurate assessment of the fluxes.

The Permian Basin currently produces 16 billion cu. ft. per day of NG (https://www.eia.gov/petroleum/drilling/pdf/ permian.pdf, last access: 20 June 2021) over an area of $220000 \mathrm{~km}^{2}$. The molar volume of an ideal gas at standard temperature and pressure (STP) is $22.4 \mathrm{~L}$. One cubic foot (cu. ft.) is $28.3 \mathrm{~L}$, so 16 billion cu. ft. is 20 billion moles of NG or $120 \times 10^{32}$ molecules per day. Over an area of $220000 \mathrm{~km}^{2}$ or $2.2 \times 10^{15} \mathrm{~cm}^{2}$, this represents an average areal production of $55 \times 10^{17}$ molecules $\mathrm{cm}^{-2} \mathrm{~d}^{-1}$. Assuming that the Permian Basin is $480 \mathrm{~km}$ wide, at an average low-level wind speed of $15 \mathrm{~km} \mathrm{~h}^{-1}$, an air parcel will take $32 \mathrm{~h}(1.33 \mathrm{~d})$ to traverse the basin, during which time $73 \times 10^{17}$ molecules $\mathrm{cm}^{-2}$ will have been extracted. Of this, $10 \%$ will be $\mathrm{C}_{3} \mathrm{H}_{8}$ (Howard et al., 2015), so if all this production were released into the atmosphere we would expect a $\mathrm{C}_{3} \mathrm{H}_{8}$ column enhancement of $73 \times 10^{16}$.

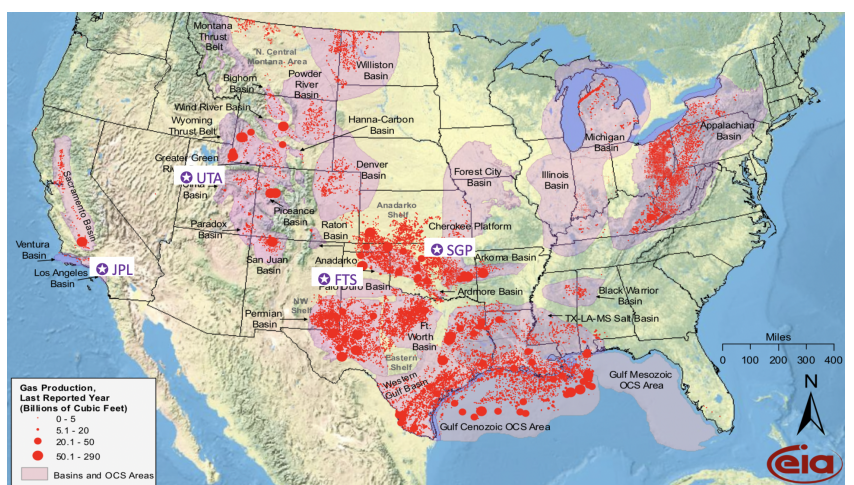

Figure 11. NG production in the lower 48 states of the USA in 2009. Data from the Energy Information Administration: https://www.eia. gov/oil_gas/rpd/conventional_gas.pdf, last access: 20 June 2021. Superimposed are the locations (purple pentangular star) of the four sites discussed in detail in this paper: Ft. Sumner in eastern New Mexico is labeled "FTS". The JPL site in California is labeled "JPL". The locations of the NOAA sites in Utah (UTA) and Oklahoma (SGP) are also included. The Permian Basin lies in the SE corner of New Mexico and western Texas.

In air masses with trajectories from the $\mathrm{SE}$, we see maximum $\mathrm{C}_{3} \mathrm{H}_{8}$ column enhancements of only $3 \times$ $10^{16}$ molecules $\mathrm{cm}^{-2}$, which suggests that only $4 \%$ of the NG escapes into the atmosphere and that $96 \%$ of the NG is successfully captured (or burned by flaring).

In the Permian Basin, $\mathrm{NG}$ is $13.7 \% \mathrm{C}_{2} \mathrm{H}_{6}$, and yet the observed ethane enhancements are slightly smaller than those of $\mathrm{C}_{3} \mathrm{H}_{8}$, suggesting that only $\sim 3 \%$ of the $\mathrm{NG}$ escapes. Assuming a $3 \%$ leak rate, there will also be an enhancement of $\mathrm{CH}_{4}$ of about $14 \times 10^{16}$ molecules $\mathrm{cm}^{-2}$, but this represents only $0.4 \%$ of the total $\mathrm{CH}_{4}$ column above Ft. Sumner and will therefore be difficult to discern in the presence of other confounding factors (stratospheric transport, varying tropopause altitude, seasonal and longer-term changes). Of course, all this analysis assumes that the Permian Basin is a uniform emitter and that the back-trajectory wind speeds are accurate. There are likely hot spots with higher-than-average emissions and regions with little NG production.

A puzzle in our findings is that when both $\mathrm{C}_{3} \mathrm{H}_{8}$ and $\mathrm{C}_{2} \mathrm{H}_{6}$ are elevated, we measure $22 \%$ more $\mathrm{C}_{3} \mathrm{H}_{8}$ than $\mathrm{C}_{2} \mathrm{H}_{6}$ (see Fig. 9). Yet independent assays of well-head wet NG find $33 \%$ more $\mathrm{C}_{2} \mathrm{H}_{6}$ than $\mathrm{C}_{3} \mathrm{H}_{8}$ in the Permian Basin (Howard et al., 2015). So we have a $55 \%$ discrepancy. We note that the $\mathrm{C}_{2} \mathrm{H}_{6}$ averaging kernel is 0.7 at the surface versus 0.9 for $\mathrm{C}_{3} \mathrm{H}_{8}$ (see Appendix B). So when these gases exceed their priors in the PBL, which is likely at high enhancements, both will be underestimated but $\mathrm{C}_{2} \mathrm{H}_{6}$ more so than $\mathrm{C}_{3} \mathrm{H}_{8}$. So this effect would cause the $\mathrm{C}_{3} \mathrm{H}_{8} / \mathrm{C}_{2} \mathrm{H}_{6}$ ratio to be $28 \%$ higher, which explains half the $55 \%$ problem. Another possibility is that the $\mathrm{C}_{3} \mathrm{H}_{8}$ coming from fugitive wet NG is augmented by leaks of LPG, stripped from wet NG. This would further enhance the $\mathrm{C}_{3} \mathrm{H}_{8}$ (and $\mathrm{C}_{4} \mathrm{H}_{10}$ ) with little $\mathrm{C}_{2} \mathrm{H}_{6}$ increase. $\mathrm{Al}$ - 
ternatively, there could be a systematic overestimate of the MkIV $\mathrm{C}_{3} \mathrm{H}_{8}$ due to a mundane multiplicative bias in the $\mathrm{C}_{3} \mathrm{H}_{8}$ spectroscopy. This would overestimate all the $\mathrm{C}_{3} \mathrm{H}_{8}$ measurements without degrading the strong correlation with $\mathrm{C}_{2} \mathrm{H}_{6}$ but seems unlikely.

\subsection{Case study: ground-based measurements from JPL}

The Jet Propulsion Laboratory $\left(34.2^{\circ} \mathrm{N} ; 118.17^{\circ} \mathrm{W} ; 0.35 \mathrm{~km}\right.$ altitude) lies at the northern edge of the Los Angeles (LA) basin. When winds are from the north (rare in summer), air quality is good. When conditions are stagnant (common in summer), pollutants accumulate, and so air quality is poor. $\mathrm{C}_{3} \mathrm{H}_{8}$ measured at JPL exhibits a very different behavior to that at Ft. Sumner. It decreases over time, exhibits little correlation with $\mathrm{C}_{2} \mathrm{H}_{6}$, and exhibits positive correlation with $\mathrm{CO}$. Figure 12 illustrates these behaviors.

The left panels of Fig. 12 show $\mathrm{XC}_{3} \mathrm{H}_{8}$ time series measured from JPL, color coded by CO. The upper-left panel shows a large decrease in $\mathrm{C}_{3} \mathrm{H}_{8}$ from 1-3 ppb in 1990 to less than $1 \mathrm{ppb}$ in 2019. This mirrors the decrease in CO over JPL (not shown) over the same period. The lower-left panel shows a large seasonal component to the $\mathrm{C}_{3} \mathrm{H}_{8}$, with a peak in late summer, when the air is most stagnant over JPL, allowing pollutants to accumulate. The highest $\mathrm{C}_{3} \mathrm{H}_{8}$ values appear red or orange (high $\mathrm{CO}$ ), while the lowest appear blue (low $\mathrm{CO})$, implying an association with $\mathrm{CO}$. This is confirmed in the upper-right panel which plots $\mathrm{C}_{3} \mathrm{H}_{8}$ directly against $\mathrm{CO}$. The right panels are color-coded by year. The $\mathrm{C}_{3} \mathrm{H}_{8}$ correlation is mostly a result of both gases having decreased over the 30-year record. But even within each year, there still remains a positive correlation. This does not necessarily mean that $\mathrm{C}_{3} \mathrm{H}_{8}$ and $\mathrm{CO}$ have the same source, but their sources are spatially coincident.

The lower-right panel shows $\mathrm{C}_{3} \mathrm{H}_{8}$ plotted versus $\mathrm{C}_{2} \mathrm{H}_{6}$. There is a weak correlation at JPL. The high $\mathrm{XC}_{2} \mathrm{H}_{6}$ values exceeding $2.0 \mathrm{ppb}$ were measured on day 314 of 2015 when JPL was downwind of the Aliso Canyon NG leak. Appendix $\mathrm{C}$ shows a HYSPLIT back-trajectory confirming this assertion. This spike can also be seen in Fig. 3. There is no $\mathrm{C}_{3} \mathrm{H}_{8}$ enhancement associated with the $\mathrm{C}_{2} \mathrm{H}_{6}$ spike, since processed NG was leaking from an underground storage facility, with the heavy hydrocarbons (e.g., $\mathrm{C}_{3} \mathrm{H}_{8}, \mathrm{C}_{4} \mathrm{H}_{10}$ ) having already been stripped out. A $2 \%$ increase in columnaveraged $\mathrm{CH}_{4}$ was also noted in the plume of the Aliso Canyon leak, as shown in Appendix C.

California accounts for less than $1 \%$ of total US natural gas production, and this has declined over the past 3 decades (https://www.eia.gov/state/analysis.php?sid=CA, last access: 20 June 2021). Although there is natural gas extraction in the LA basin, this is a small source compared with the Permian Basin. The local natural gas is only $3 \% \mathrm{C}_{2} \mathrm{H}_{6}$ and $0.3 \% \mathrm{C}_{3} \mathrm{H}_{8}$, (https: //www.socalgas.com/stay-safe/pipeline-and-storage-safety/ playa-del-rey-storage-operations, last access: 20 June 2021) and so cannot account for the approximately equal amounts of these gases measured at JPL by the MkIV. We speculate that the $\mathrm{C}_{3} \mathrm{H}_{8}$ measured at JPL comes mainly from LPG (e.g., used in "clean" commercial vehicles, BBQ grills, external heaters, etc.). We can certainly rule out the possibility that the $\mathrm{C}_{3} \mathrm{H}_{8}$ measured at JPL is the result of wild fires, since these have increased in recent years, whereas the $\mathrm{C}_{3} \mathrm{H}_{8}$ has decreased.

\subsection{Comparison with in situ measurements}

First it should be pointed out that the column-average mole fractions that are derived from the column measurements will underestimate the gas amount in the PBL for gases like $\mathrm{C}_{2} \mathrm{H}_{6}$ and $\mathrm{C}_{3} \mathrm{H}_{8}$ that reside mainly in the PBL. For example, if $\mathrm{C}_{3} \mathrm{H}_{8}$ resides entirely between 1000 and 800 mbar, with none in the free troposphere or stratosphere, then the columnaverage values will be 5 times smaller than the actual mole fractions in the PBL. So direct comparisons of the remote and in situ mole fractions should be avoided. But their behavior as a function of year or season, or gas-to-gas correlations, can still be meaningfully compared. This effect is in addition to the effect of their averaging kernels being less than 1.0 at the surface, which was discussed earlier.

In situ $\mathrm{C}_{3} \mathrm{H}_{8}$ and $\mathrm{C}_{2} \mathrm{H}_{6}$ mole fractions from the Wendover, Utah (UTA), and Southern Great Plains, Oklahoma (SGP), sites were downloaded from the NOAA Global Monitoring Laboratory website: (https://www.esrl.noaa.gov/gmd/dv/ data/, last access: 20 June 2021). These sites are the closest to Ft. Sumner. These are surface flask measurements covering the period 2006 to 2017. Figure 13 illustrates these data as a function of the year (left panels), the day of the year (middle panels), and the $\mathrm{C}_{3} \mathrm{H}_{8}-\mathrm{C}_{2} \mathrm{H}_{6}$ relationship (right panels). The upper panels cover the UTA site and the lower panels the SGP site. Note the factor 10 change in the $y$ scale: there is 10 times more of these gases at SGP than at UTA. Looking at the map in Fig. 11, this is clearly because SGP lies immediately downwind of the Anadarko Basin oil and NG fields under the prevailing WSW winds. In contrast, the UTA site has no major upwind source.

These in situ measurements confirm that $\mathrm{C}_{3} \mathrm{H}_{8}$ is highly variable with large enhancements being associated with oil and $\mathrm{NG}$ production fields. At SGP the $\mathrm{C}_{3} \mathrm{H}_{8} / \mathrm{C}_{2} \mathrm{H}_{6}$ ratio is about 0.65 . This is smaller than those measured by the MkIV, but NG in the Permian Basin is much wetter (richer in $\mathrm{C}_{3} \mathrm{H}_{8}$ ) than in the Anadarko Basin.

\subsection{Balloon results}

We also attempted to retrieve $\mathrm{C}_{3} \mathrm{H}_{8}$ from MkIV balloon solar occultation spectra. It was not detected in any flight, despite a very good sensitivity of $0.05 \mathrm{ppb}$ above $5 \mathrm{~km}$. This confirms that the $\mathrm{C}_{3} \mathrm{H}_{8}$ detected in ground-based measurements, reaching column-average mole fractions of up to $4 \mathrm{ppb}$, resides mostly in the PBL. The balloon launches are typically 

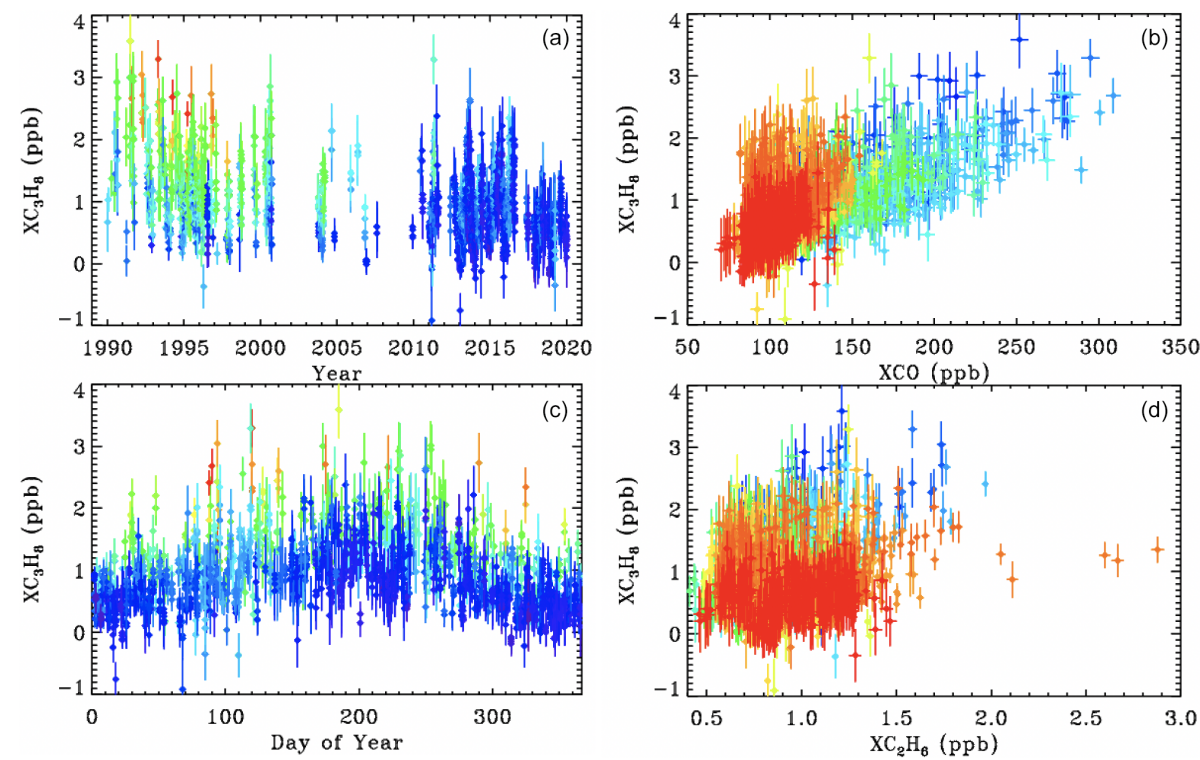

Figure 12. Column-average $\mathrm{C}_{3} \mathrm{H}_{8}$ above JPL. Left-hand panels $((\mathbf{a}, \mathbf{c}))$ show the time series color-coded by $\mathrm{XCO}$ (red $=250$, green $=130$, blue $=100 \mathrm{ppb})$. Right-hand panels $((\mathbf{b}, \mathbf{d}))$ show the relationship between $\mathrm{XC}_{3} \mathrm{H}_{8}, \mathrm{XCO}$, and $\mathrm{XC}_{2} \mathrm{H}_{6}$ color-coded by year $($ blue $=1990$; green $=2005 ;$ red $=2019$ ).
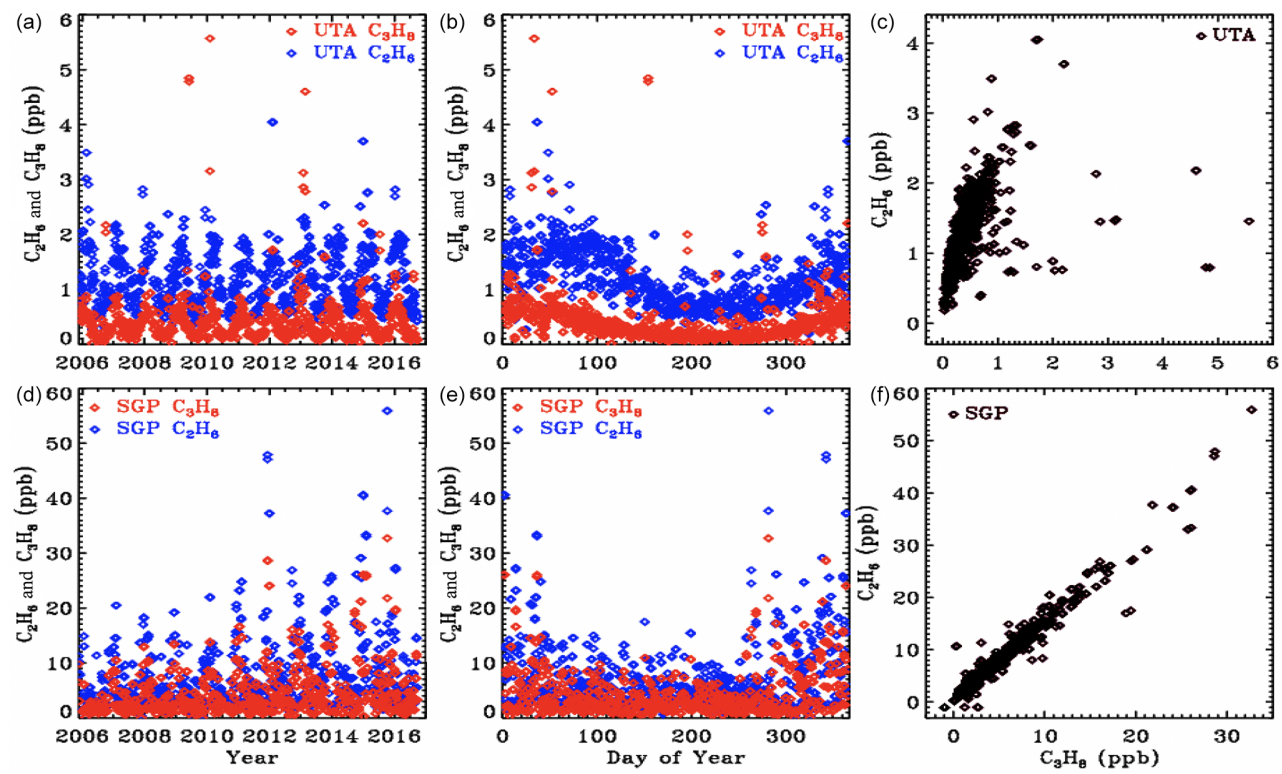

Figure 13. In situ flask measurements of $\mathrm{C}_{3} \mathrm{H}_{8}$ (red) and $\mathrm{C}_{2} \mathrm{H}_{6}$ (blue) from the NOAA ESRL GMD dataset (Helmig et al., 2009). Upper panels ((a), (b), (c)) show results from the UTA site. Lower panels ((d), (e), (f)) are from SGP. Note the factor 10 change in the $y$ scale between the two sites. Left-hand panels $((\mathbf{a}),(\mathbf{d}))$ plot data versus year to illustrate secular trends. Middle panels ((b), (e)) plot data versus day of year to more clearly see the seasonal cycle. Right-hand panels ((c), (f)) plot $\mathrm{C}_{3} \mathrm{H}_{8}$ versus $\mathrm{C}_{2} \mathrm{H}_{6}$.

performed only under stable, quiescent, meteorological conditions with light surface winds. Such conditions preclude uplift of air from the PBL into the free troposphere, so that $\mathrm{C}_{3} \mathrm{H}_{8}$ stays confined to the $\mathrm{PBL}$, which is opaque in limb paths due to aerosol and so cannot be probed in occultation. This does not preclude $\mathrm{C}_{3} \mathrm{H}_{8}$ rising up into the free troposphere at other times or in other places.

\section{Summary and conclusions}

We report measurements of atmospheric $\mathrm{C}_{3} \mathrm{H}_{8}$ by solar absorption spectrometry in the strong $Q$-branch region at $2957 \mathrm{~cm}^{-1}$, using high-resolution IR spectra from the JPL MkIV interferometer. To the best of our knowledge, these are the first remote sensing measurements of at- 
mospheric $\mathrm{C}_{3} \mathrm{H}_{8}$. The minimum detectable abundance is about $10^{16}$ molecules $\mathrm{cm}^{-2}$, which is roughly equivalent to a column-average mole fraction of $0.5 \mathrm{ppb}$. This allows $\mathrm{C}_{3} \mathrm{H}_{8}$ to be measured in locations where its abundance is enhanced by proximity to sources (e.g., large gas fields, megacities) but not in clean locations (e.g., above the PBL or away from sources). We encourage such NDACC (Network for the Detection of Atmospheric Composition Change) and TCCON sites to examine their datasets for $\mathrm{C}_{3} \mathrm{H}_{8}$. Future improvements to the spectroscopy of the interfering gases, e.g., $\mathrm{H}_{2} \mathrm{O}$, $\mathrm{CH}_{4}, \mathrm{C}_{2} \mathrm{H}_{6}$, and other $\mathrm{CH}$-containing gases currently missing, might even provide for the detection of $\mathrm{C}_{3} \mathrm{H}_{8}$ from clean sites at background levels, allowing it to become a routine product of the NDACC and TCCON networks.

A case study of ground-based MkIV measurements from Ft. Sumner, New Mexico, shows increasing $\mathrm{C}_{3} \mathrm{H}_{8}$ and $\mathrm{C}_{2} \mathrm{H}_{6}$ amounts in the past decade on days when back-trajectories came from southeastern New Mexico and western Texas, where the Permian Basin oil and gas field is located. A case study of $\mathrm{C}_{3} \mathrm{H}_{8}$ measured at JPL shows a long-term decrease since 1990 by more than a factor of 2 . It also shows a strong correlation with $\mathrm{CO}$, a tracer of urban pollution. There is no significant correlation between $\mathrm{C}_{3} \mathrm{H}_{8}$ and $\mathrm{C}_{2} \mathrm{H}_{6}$ at JPL.

The MkIV measurements in the case studies are not particularly useful for determining the long-term global trends in $\mathrm{C}_{3} \mathrm{H}_{8}$ or $\mathrm{C}_{2} \mathrm{H}_{6}$, due to their close proximity to strong sources. In the case of Ft. Sumner, the source is the Permian Basin. In the case of JPL, the source is the Los Angeles urban area with a population of $\sim 15$ million. These sources cause large meteorology-driven fluctuations that mask the longer-term trends.

From balloon measurements in solar occultation, propane was analyzed using the same window as for the groundbased measurements. It was not detected at any altitude in any of our 25 flights, despite a 0.05 ppb detection limit. This is presumably because under the stable atmospheric conditions that allow balloon launches, $\mathrm{C}_{3} \mathrm{H}_{8}$ stays confined to the $\mathrm{PBL}$, which is opaque in the limb viewing geometry and so cannot be probed. 


\section{Appendix A: Correlations between retrieved parameters}

We compute Pearson correlation coefficients (PCCs) from the a posteriori covariance matrix for each of the $5000 \mathrm{spec}-$ tral fits. The upper panel of Fig. A1 shows the PCCs between retrieved $\mathrm{C}_{3} \mathrm{H}_{8}$ and $\mathrm{C}_{2} \mathrm{H}_{6}$. Points are plotted versus year with the same site-altitude-dependent coloring as in the other figures. The PCCs between $\mathrm{C}_{3} \mathrm{H}_{8}$ and $\mathrm{C}_{2} \mathrm{H}_{6}$ averages about -0.7 , which means that they are fairly strongly anticorrelated. This is due to their overlapping absorption features at $2967.5 \mathrm{~cm}^{-1}$. So as retrieved $\mathrm{C}_{2} \mathrm{H}_{6}$ increases, retrieved $\mathrm{C}_{3} \mathrm{H}_{8}$ will decrease and vice versa. The PCCs are closer to zero for the high-altitude sites (red and orange), presumably due to the reduced pressure broadening and $\mathrm{H}_{2} \mathrm{O}$ causing the $\mathrm{C}_{2} \mathrm{H}_{2}$ and $\mathrm{C}_{2} \mathrm{H}_{6}$ absorption features to become more distinct. This anticorrelation could be reduced by use of a wider window to introduce additional $\mathrm{C}_{2} \mathrm{H}_{6}$ features that do not correlate with $\mathrm{C}_{3} \mathrm{H}_{8}$, but this would also encompass large residuals without adding any $\mathrm{C}_{3} \mathrm{H}_{8}$ information.
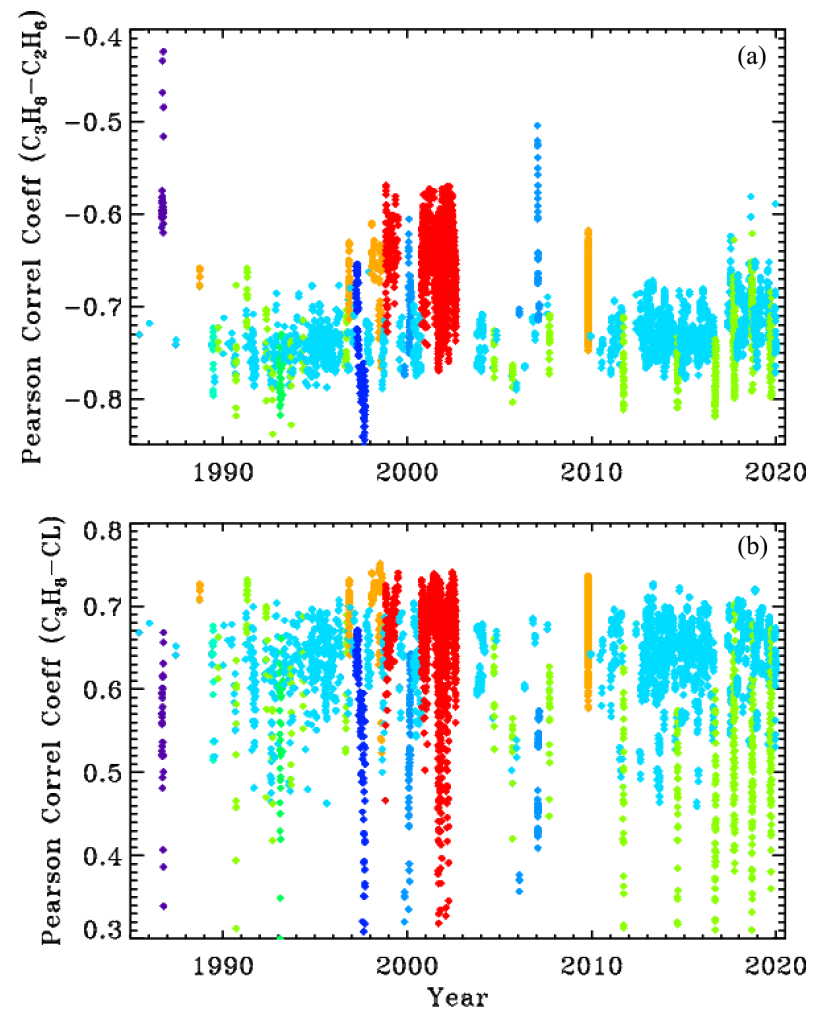

Figure A1. Pearson correlation coefficients between $\mathrm{C}_{3} \mathrm{H}_{8}$ and $\mathrm{C}_{2} \mathrm{H}_{6}$ (a) and between $\mathrm{C}_{3} \mathrm{H}_{8}$ and the continuum level (CL) (b).
The $\mathrm{C}_{3} \mathrm{H}_{8}-\mathrm{CL}$ correlations are about +0.65 at low SZA, decreasing at higher SZA as the $\mathrm{H}_{2} \mathrm{O}$ and $\mathrm{CH}_{4}$ absorptions black out the window. So the more $\mathrm{C}_{3} \mathrm{H}_{8}$ that is retrieved, the higher the continuum level has to be to match the measured spectrum, due to the fact that the $\mathrm{C}_{3} \mathrm{H}_{8}$ absorption spectrum has a broad continuum-like component beneath the $Q$-branch. The PCCs between $\mathrm{C}_{3} \mathrm{H}_{8}$ and the other retrieved parameters (e.g., $\mathrm{H}_{2} \mathrm{O}, \mathrm{HDO}, \mathrm{CH}_{4}$, continuum tilt, frequency shifts) were all much closer to zero than with $\mathrm{C}_{2} \mathrm{H}_{6}$ and CL.

The high $\mathrm{PCC}$ between $\mathrm{C}_{3} \mathrm{H}_{8}$ and $\mathrm{C}_{2} \mathrm{H}_{6}$ does not necessarily imply a large uncertainty in the $\mathrm{C}_{3} \mathrm{H}_{8}$. It just means that the large component of the $\mathrm{C}_{2} \mathrm{H}_{6}$ uncertainty gets projected onto the $\mathrm{C}_{3} \mathrm{H}_{8}$. Ditto for the CL. But provided the $\mathrm{C}_{2} \mathrm{H}_{6}$ and $\mathrm{CL}$ are well retrieved, their effect on the $\mathrm{C}_{3} \mathrm{H}_{8}$ will not dominate. 
Appendix B: Sensitivity of retrieved $\mathrm{C}_{3} \mathrm{H}_{8}$ columns to assumed $P, T$, and $\mathrm{H}_{2} \mathrm{O}$ profiles

The retrievals shown in the main body of the paper were performed using 6-hourly NCEP analyses of $T, P$, and $\mathrm{H}_{2} \mathrm{O}$, as used in the GGG TCCON analyses (Wunch et al., 2011). Due to the overlap of strong $\mathrm{H}_{2} \mathrm{O}$ and $\mathrm{CH}_{4}$ lines with the $\mathrm{C}_{3} \mathrm{H}_{8} Q$-branch, we were concerned that small errors in the assumed $T / P / \mathrm{H}_{2} \mathrm{O} / \mathrm{CH}_{4}$ priors might strongly influence the retrieved $\mathrm{C}_{3} \mathrm{H}_{8}$. We therefore re-retrieved $\mathrm{C}_{3} \mathrm{H}_{8}$ over the 2000-2020 period using the GEOS-FP-IT 3-hourly analyses, which forms the basis of the latest (GGG2020) TCCON analysis (Laughner et al., 2021). We would have done the entire analysis with the GEOS-FP-IT model except that it only supports the post-2000 time period.

Figure $\mathrm{B} 1$ compares the retrieved $\mathrm{C}_{3} \mathrm{H}_{8}$ columns with the two analysis methods: NCEP in the left panels and GEOSFP-IT in the right panels. The results look very similar.
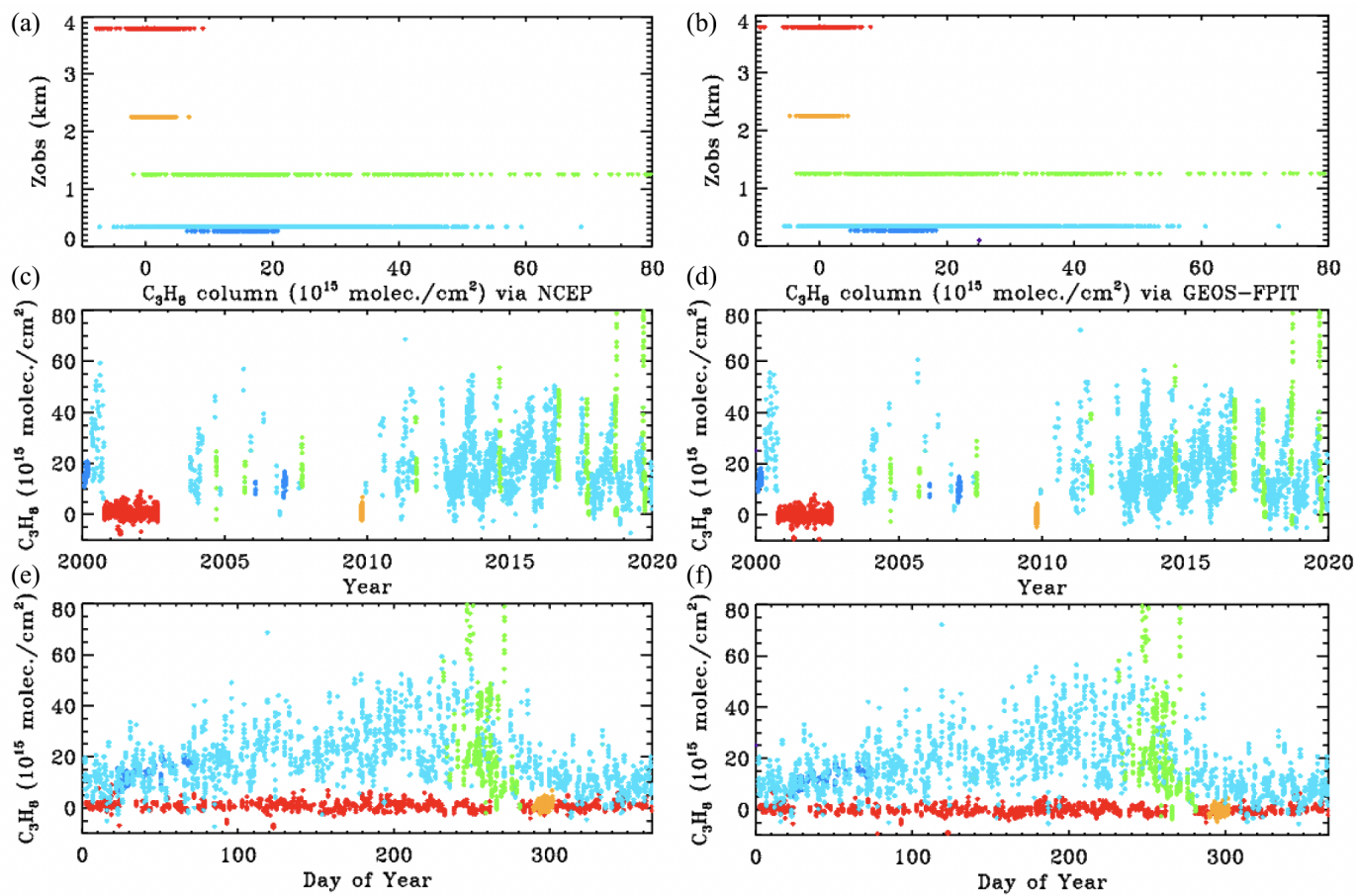

Figure B1. Retrieved vertical columns of $\mathrm{C}_{3} \mathrm{H}_{8}$ from 2000 to 2020 using two different atmospheric models. (a) NCEP a priori $T / P / \mathrm{H}_{2} \mathrm{O}$. (b) GEOS-FP-IT a priori $T / P / \mathrm{H}_{2} \mathrm{O}$. Points are color-coded by site altitude, as in Fig. 3. 
Figure B2 examines more closely the $\mathrm{C}_{3} \mathrm{H}_{8}$ columns from the two analyses. In the upper panel the NCEP and GEOSFP-IT columns are plotted against each other. The gradient is $1.011 \pm 0.003$ with NCEP producing slightly larger columns. The Pearson correlation coefficient is +0.979 . The column differences, shown in the lower panel, are mostly less than $5 \times 10^{15}$ and are centered around zero at all column amounts. So the choice of models and priors makes surprisingly little difference to the retrieved $\mathrm{C}_{3} \mathrm{H}_{8}$. This does not mean that the $\mathrm{C}_{3} \mathrm{H}_{8}$ is highly accurate. There are many things that are identical in the two analyses (e.g., spectroscopy, retrieval code, spectra), which could nevertheless contribute large errors to the retrieved $\mathrm{C}_{3} \mathrm{H}_{8}$.
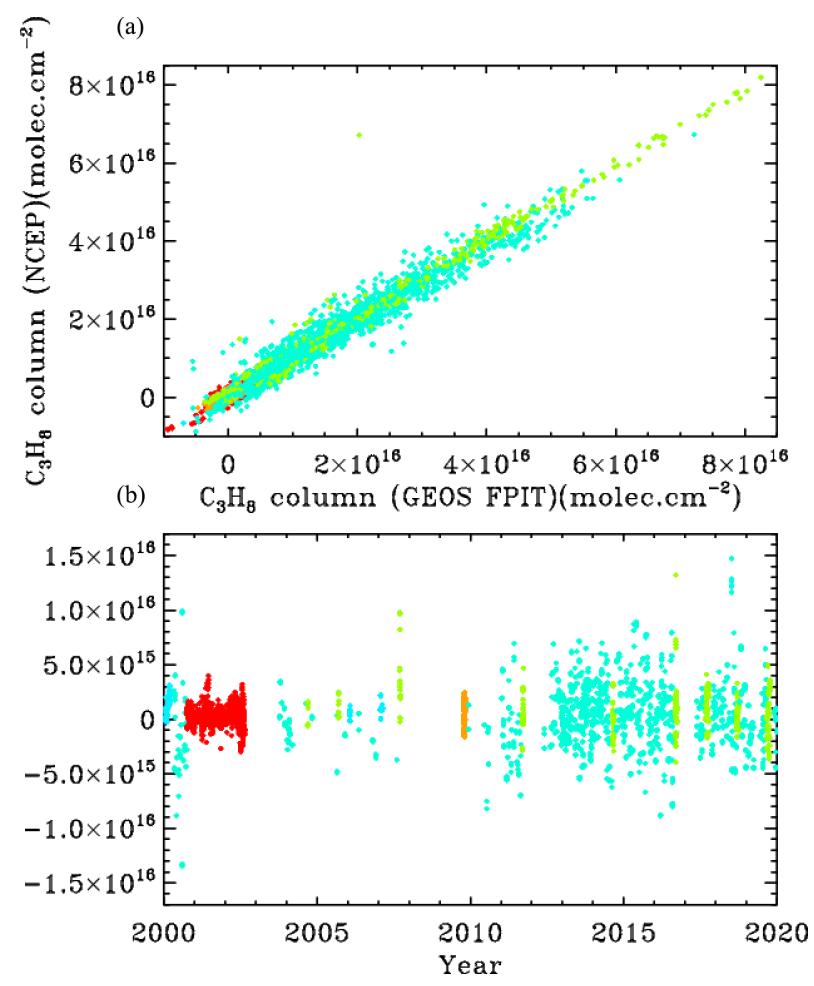

Figure B2. Comparing the $\mathrm{C}_{3} \mathrm{H}_{8}$ columns retrieved from the 6hourly NCEP and the 3-hourly GEOS-FP-IT priors, color-coded by site altitude, as in Fig. 3. In the upper panel the columns are plotted against each other. In the lower panel their difference is plotted. 


\section{Appendix C: Aliso Canyon underground storage facility: gas leak in late 2015}

Aliso Canyon underground storage facility (USF) is located $30 \mathrm{~km} \mathrm{NW}$ of JPL. According to the 4 January 2016 Los Angeles Times, the NG leak began on 23 October 2015 and peaked on 28 November at $60 \mathrm{tCH}_{4} \mathrm{~h}^{-1}$. By 22 December, the leak rate had decreased to $30 \mathrm{th}^{-1}$ as the underground storage pressure dropped from the initial $2700 \mathrm{psi}$.

Large $\mathrm{C}_{2} \mathrm{H}_{6}$ amounts (3 times normal) were observed from JPL on 10 November (day 314) but with no enhancement of $\mathrm{C}_{3} \mathrm{H}_{8}$. HYSPLIT back-trajectories for this day indicate that the air arriving at JPL at $1000 \mathrm{~m}$ above ground was from the northwest and had passed over Aliso Canyon USF, confirming that the air over JPL was contaminated by the leak.

Most of the variation in column $\mathrm{CH}_{4}$ and $\mathrm{N}_{2} \mathrm{O}$ is associated with the stratospheric circulation. Old air masses from high latitudes are depleted in $\mathrm{CH}_{4}$ and $\mathrm{N}_{2} \mathrm{O}$. To remove these effects and to be able to more clearly see changes driven by the troposphere, $\mathrm{XCH}_{4}$ is plotted versus $\mathrm{XN}_{2} \mathrm{O}$, which is similarly affected by stratospheric circulation but not by tropospheric emissions. This creates a correlation with the lowerleft points representing high-latitude stratospheric air masses and the upper-right low-latitude air masses.

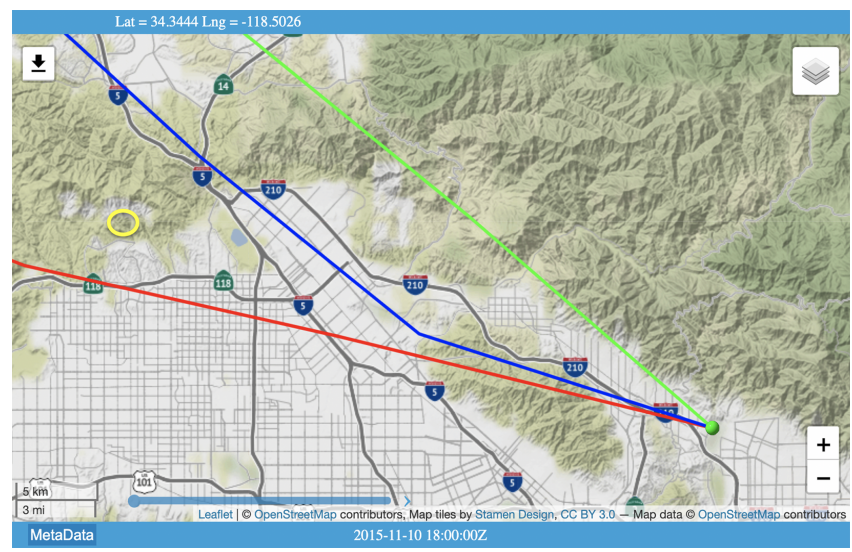

Figure C1. HYSPLIT back-trajectories for 10 November 2015 (day 314) when the highest ever $\mathrm{C}_{2} \mathrm{H}_{6}$ level was measured from JPL. Yellow oval (upper left) indicates the location of Aliso Canyon underground storage facility. Green ball (lower right) denotes JPL, at the convergence of trajectories arriving at 19:00, 20:00, and 21:00 UT. Trajectory calculation used the North American Model (NAM) $12 \mathrm{~km}$ resolution, hybrid sigma-pressure meteorology. (C) OpenStreetMap contributors 2020. Distributed under a Creative Commons BY-SA License.

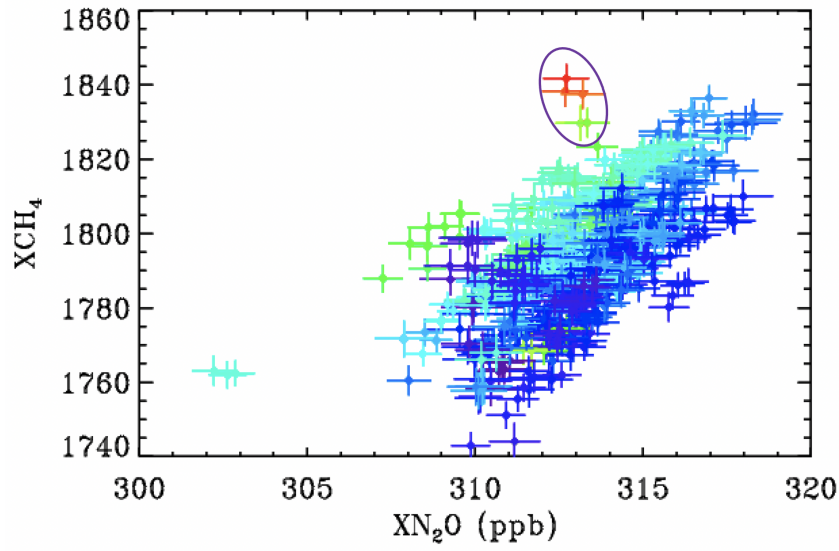

Figure C2. Showing the relationship between $\mathrm{CH}_{4}$ and $\mathrm{N}_{2} \mathrm{O}$ at JPL during 2014-2017 color-coded by $\mathrm{C}_{2} \mathrm{H}_{6}$. Blue points represent low $\mathrm{C}_{2} \mathrm{H}_{6}$ level, whereas red represents the highest $\mathrm{C}_{2} \mathrm{H}_{6}$. The encircled points represent 10 November 2015, whose back-trajectory is shown in the previous figure.

The encircled points in Fig. C2 were measured on 10 November 2015, when JPL was downwind of the Aliso Canyon USF leak. This indicates $\mathrm{XCH}_{4}$ enhancements of over $2 \%$, which probably represent more than $10 \%$ enhancement in the PBL with no enhancement above. There is also a general tendency for higher $\mathrm{CH}_{4}$ values when $\mathrm{C}_{2} \mathrm{H}_{6}$ is elevated on other days too, as seen from the dark blue points (low $\mathrm{C}_{2} \mathrm{H}_{6}$ ) being predominantly in the lower right of the figure and the greener points (higher $\mathrm{C}_{2} \mathrm{H}_{6}$ ) being located toward the upper left. 
Code availability. The GFIT code used for the analysis of MkIV spectra is identical to that used by the TCCON project. It is publicly available under license from the California Institute of Technology for non-commercial use. It can be cloned from hg clone https: //parkfalls.gps.caltech.edu/tccon/stable/hg/ggg-stable/, last access: 20 June 2021 (after signing the license agreement and being issued a password).

Data availability. The ground-based MkIV data used in this paper can be downloaded from two sites: https://mark4sun.jpl.nasa.gov/ ground.html, last access: 20 June 2021 and ftp://ftp.cpc.ncep.noaa. gov/ndacc/station/barcroft/ames/ftir/, last access: 20 June 2021.

Author contributions. GCT, KS, and JFLB contributed to data acquisition. GCT and KY contributed to data interpretation.

Competing interests. The authors declare that they have no conflict of interest.

Acknowledgements. The authors gratefully acknowledge the NOAA Air Resources Laboratory (ARL) for the provision of the HYSPLIT transport and dispersion model and/or READY website (https://www.ready.noaa.gov, last access: 7 April 2021) used in this publication. We thank NCEP and GEOS-FP-IT for their atmospheric analyses. We also acknowledge the NOAA ESRL GMD for distributing in situ data of $\mathrm{C}_{3} \mathrm{H}_{8}$ and $\mathrm{C}_{2} \mathrm{H}_{6}$. The research was carried out at the Jet Propulsion Laboratory, California Institute of Technology, under a contract with the National Aeronautics and Space Administration (80NM0018D0004).

Financial support. This research has been supported by the NASA's Upper Atmosphere Composition Observation (UACO) program.

Review statement. This paper was edited by Gabriele Stiller and reviewed by Debra Wunch and two anonymous referees.

\section{References}

Angelbratt, J., Mellqvist, J., Simpson, D., Jonson, J. E., Blumenstock, T., Borsdorff, T., Duchatelet, P., Forster, F., Hase, F., Mahieu, E., De Mazière, M., Notholt, J., Petersen, A. K., Raffalski, U., Servais, C., Sussmann, R., Warneke, T., and Vigouroux, C.: Carbon monoxide $(\mathrm{CO})$ and ethane $\left(\mathrm{C}_{2} \mathrm{H}_{6}\right)$ trends from ground-based solar FTIR measurements at six European stations, comparison and sensitivity analysis with the EMEP model, Atmos. Chem. Phys., 11, 9253-9269, https://doi.org/10.5194/acp11-9253-2011, 2011.

Conley, S.,Franco, G., Faloona, I., Blake, D. R.,, Peischl, and Ryerson, T. B.: Methane emissions from the 2015 Aliso Canyon blowout in Los Angeles, Science, 351, 1317-1320, 2016.
Dalsøren, S. B., Myhre, G., Hodnebrog, Ø., Lund Myhre, C., Stohl, A, Pisso, I., Schwietzke, S., Höglund-Isaksson, L., Helmig, D., Reimann, S., Sauvage, S., Schmidbauer, N., Read, K. A., Carpenter, L. J., Lewis, A. C., Punjabi, S., and Wallasch, M.: Discrepancy between simulated and observed ethane and propane levels explained by underestimated fossil emissions, Nat. Geosci., 11, 178-184, https://doi.org/10.1038/s41561-018-0073-0, 2018.

Franco, B., Bader, W., Toon, G., Bray, C., Perrin, A., Fischer, E., Sudo, K., Boone, C., Bovy, B., Lejeune, B., Servais, C., and Mahieu, E.: Retrieval of ethane from ground-based FTIR solar spectra using improved spectroscopy: recent burden increase above Jungfraujoch, J. Quant. Spec. Radiat. Trans., 160, 36-49, 2015.

Franco, B., Mahieu, E., Emmons, L., Tzompa-Sosa, Z., Fischer, E., Sudo, K., Bovy, B., Conway, S., Griffin, D., Hannigan, J., Strong, K., and Walker, K.: Evaluating ethane and methane emissions associated with the development of oil and natural gas extraction in North America, Environ. Res. Lett., 11, 044010, https://doi.org/10.1088/1748-9326/11/4/044010, 2016.

Harrison, J. J. and Bernath, P. F.: Infrared absorption cross sections for propane $\left(\mathrm{C}_{3} \mathrm{H}_{8}\right)$ in the $3 \mu \mathrm{m}$ region, J. Quant. Spectrosc. Ra., 111, 1282-1288, https://doi.org/10.1016/j.jqsrt.2009.11.027, 2010.

Harrison, J. J., Allen, N. D. C., and Bernath, P. F.: Infrared absorption cross sections for ethane $\left(\mathrm{C}_{2} \mathrm{H}_{6}\right)$ in the $3 \mu \mathrm{m}$ region: J. Quant. Spectrosc. Ra., 111, 357-363, https://doi.org/10.1016/j.jqsrt.2009.09.010, 2010.

Helmig, D., Muñoz, M., Hueber, J., Mazzoleni, C., Mazzoleni, L., Owen, R.C., Val-Martin, M., Fialho, P., Plass-Duelmer, C., Palmer, P., Lewis, A., and Pfister, G.: Climatology and atmospheric chemistry of the non-methane hydrocarbons ethane and propane over the North Atlantic, Elementa, 3, 000054, https://doi.org/10.12952/journal.elementa.000054, 2015.

Helmig, D., Rossabi, S., Hueber, J., Tans, P., Montzka, S. A., Masarie, K., Thoning, K., Plass-Duelmer, C., Claude, A., Carpenter, L. J., Lewis, A. C., Punjabi, S., Reimann, S., Vollmer, M. K., Steinbrecher, R., Hannigan, J., Emmons, L. K., Mahieu, E., Franco, B., Smale, D., and Pozzer, A.: Reversal of global atmospheric ethane and propane trends largely due to US oil and natural gas production, Nat. Geosci., 9, 490-495, https://doi.org/10.1038/ngeo2721, 2016.

Helmig, D., Bottenheim, J., Galbally, I. E., Lewis, A., Milton, M. J. T., Penkett, S., Plass-Duelmer, C., Reimann, S., Tans, P., and Thiel, S.: Volatile Organic Compounds in the Global Atmosphere, Eos Trans. AGU, 90, 513-514, https://doi.org/10.1029/2009EO520001, 2009.

Howard, T., Ferrara, T. W., and Townsend-Small, A.: Sensor transition failure in the high flow sampler: Implications for methane emission inventories of natural gas infrastructure, J. Air Waste Manag. Assoc., 65, 856-862, https://doi.org/10.1080/10962247.2015.1025925, 2015.

Irion, F. W., Gunson, M. R., Toon, G. C., Chang, A. Y., Eldering, A., Mahieu, E., Manney, G. L., Michelsen, H. A., Moyer, E. J., Newchurch, M. J., Osterman, G. B., Rinsland, C. P., Salawitch, R. J., Sen, B., Yung, Y. L., and Zander, R.: Atmospheric Trace Molecule Spectroscopy (ATMOS) Experiment Version 3 data retrievals, Appl. Opt., 41, 6968-6979, 2002. 
Rolph, G., Stein, A., and Stunder, B.: Real-time Environmental Applications and Display sYstem: READY, Environ. Modell. Softw., 95, 210-228, 2017.

Rosado-Reyes, C. M. and Francisco, J. S.: Francisco, Atmospheric oxidation pathways of propane and its by-products: Acetone, acetaldehyde, and propionaldehyde, J. Geophys. Res., 112, D14310, https://doi.org/10.1029/2006JD007566, 2007.

Sharpe, S. W., Johnson, T. J., Sams, R. L., Chu, P. M., Rhoderick, G. C., and Johnson, P. A.: Gas-Phase Databases for Quantitative Infrared Spectroscopy, Appl. Spectrosc., 58, 1452-1461, 2004.

Stein, A. F., Draxler, R. R, Rolph, G. D., Stunder, B. J. B., Cohen, M. D., and Ngan, F.: NOAA's HYSPLIT atmospheric transport and dispersion modeling system, Bull. Am. Meteorol. Soc., 96, 2059-2077, 2015.

Sung, K., Toon, G., Mantz, A. W., and Smith, M. A. H.: FTIR measurements of cold $\mathrm{C} 3 \mathrm{H} 8$ cross sections at $7-15 \mu \mathrm{m}$ for Titan atmosphere, Icarus, 226, 1499-1513, https://doi.org/10.1016/j.icarus.2013.07.028, 2013.

Toon, G. C.: The JPL MkIV Interferometer, Opt. Photon. News, 2, 19-21, 1991.
Toon, G. C., Blavier, J.-F., Sung, K., Rothman, L. S., and Gordon, I.: HITRAN spectroscopy evaluation using solar occultation FTIR spectra, J. Quant. Spectrosc. Ra., 182, 324-336, https://doi.org/10.1016/j.jqsrt.2016.05.021, 2016.

Toon, G. C., Blavier, J.-F. L., and Sung, K.: Atmospheric carbonyl sulfide (OCS) measured remotely by FTIR solar absorption spectrometry, Atmos. Chem. Phys., 18, 1923-1944, https://doi.org/10.5194/acp-18-1923-2018, 2018 a.

Toon, G. C., Blavier, J.-F. L., and Sung, K.: Measurements of atmospheric ethene by solar absorption FTIR spectrometry, Atmos. Chem. Phys., 18, 5075-5088, https://doi.org/10.5194/acp18-5075-2018, 2018b.

Wunch, D., Toon, G. C., Blavier, J.-F. L., Washenfelder, R. A., Notholt, J., Connor, B. J., Griffith, D. W. T., Sherlock, V., and Wennberg, P. O.: The total carbon column observing network, Philos. T. R. Soc. A, 369, 2087-2112, https://doi.org/10.1098/rsta.2010.0240, 2011. 